Technological University Dublin

DÜBLIN

ARROW@TU Dublin

\title{
Computational Development of Selective nNOS Inhibitors: Binding Modes and Pharmacokinetic Considerations
}

\author{
Adam Curtin \\ National University of Ireland, Maynooth \\ Gemma K. Kinsella \\ Technological University Dublin, gemma.kinsella@tudublin.ie \\ John Stephens \\ National University of Ireland, Maynooth
}

Follow this and additional works at: https://arrow.tudublin.ie/schfsehart

Part of the Environmental Health and Protection Commons

\section{Recommended Citation}

Curtin, A., Kinsella, K. and Stephens, J (2015) Computational Development of Selective nNOS Inhibitors: Binding Modes and Pharmacokinetic Considerations Current medicinal chemistry, 2015, (22), April 2015 DOI: $10.2174 / 0929867322666150429112600 \cdot d$

This Article is brought to you for free and open access by the School of Food Science and Environmental Health at ARROW@TU Dublin. It has been accepted for inclusion in Articles by an authorized administrator of ARROW@TU Dublin. For more information, please contact arrow.admin@tudublin.ie, aisling.coyne@tudublin.ie, gerard.connolly@tudublin.ie.

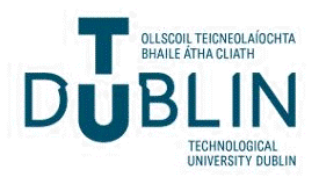




\title{
Computational Development of Selective nNOS Inhibitors: Binding Modes and Pharmacokinetic Considerations
}

\author{
Adam M. Curtin ${ }^{1}$, Gemma K. Kinsella ${ }^{2,{ }^{*}}$ and John C. Stephens, ${ }^{1, *}$
}

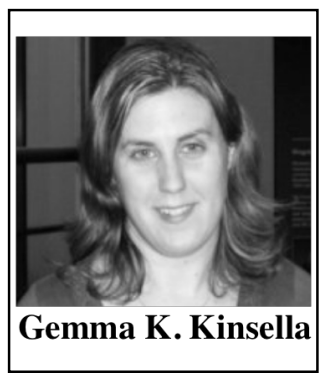

\author{
${ }^{1}$ Department of Chemistry, Maynooth University, National University of \\ Ireland Maynooth, Maynooth, Co. Kildare, Ireland; ${ }^{2}$ School of Food Science \\ and Environmental Health, College of Sciences and Health, Dublin Institute of \\ Technology, Cathal Brugha Street, Dublin 1, Ireland
}

Abstract: Neuronal nitric oxide synthase (nNOS) produces the key signalling mediator nitric oxide, (NO). This gaseous, free radical molecule modulates a vast array of biological processes, from vascular pressure to immune responses and neurological signalling cascades. Overproduction of NO has been implicated in conditions including Alzheimer's disease, Parkinson's disease and schizophrenia. Inhibition of nNOS

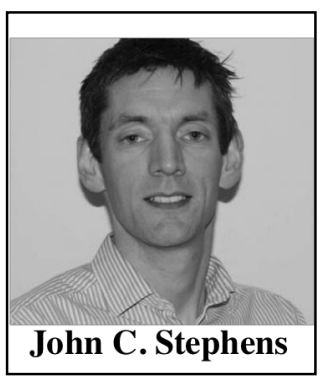
therefore offers a potential therapeutic approach for treatment of these conditions. This endeavour is made more complex by the fact that there are two other isoforms of nitric oxide synthase (NOS), endothelial NOS (eNOS) and inducible NOS (iNOS). The selectivity of nNOS inhibitors is therefore a key concern for therapeutic development. This review explores recent advances in the field of selective nNOS inhibition. A particular focus is placed on computational approaches towards the rational design of selective nNOS ligands with improved pharmacokinetic properties. These ligands have been targeted at four key binding sites of the nNOS enzyme - the tetrahydrobiopterin, calmodulin, nicotinamide adenine dinucleotide phosphate (NADPH) and arginine binding sites. The binding sites, and the compounds used to inhibit them, will be discussed in turn, along with the computational methods which have been employed in the field of nNOS inhibition.

Keywords: Binding pockets, in silico, neuronal nitric oxide synthase (nNOS), selective inhibition.

\section{INTRODUCTION}

\subsection{NOS Function}

Nitric oxide (NO) is a small, gaseous, free radical molecule which acts as a vital secondary messenger for a variety of physiological functions. NO exerts its signalling effect by stimulation of the cyclic guanosine 3',5'-monophosphate (cGMP) pathway, causing an increase in production of cGMP and activation of phosphorylation events [1-3]. cGMP signalling cascades have been directly linked to a plethora of neuronal and cardiovascular actions, including long term memory formation and vascular pressure regulation [4]. NO is also directly employed as a reactive oxygen species (ROS) to combat foreign pathogens and tumours [5].

NO is produced by a family of enzymes called the nitric oxide synthases (NOS). These enzymes convert L-arginine and molecular oxygen to $\mathrm{NO}$ and L-citrulline via a $\mathrm{N}$ hydroxy-L-arginine (L-NOHA) intermediate (Fig. 1) [6].

\footnotetext{
*Address correspondence to these authors at the School of Food Science and Environmental Health, College of Sciences and Health, Dublin Institute of Technology, Cathal Brugha Street, Dublin 1, Ireland;

Tel: +35301 402-7541; E-mail: Gemma.kinsella@dit.ie and Department of Chemistry, Maynooth University, National University of Ireland Maynooth, Maynooth, Co. Kildare, Ireland; Tel: +353 01 708-6942; Fax: +353 01 7083815 ; E-mail: John.stephens@nuim.ie
}

There are three mammalian isoforms of the enzyme. Endothelial NOS (eNOS), produces NO for use in the vascular system where it regulates vasodilation and vascular pressure [7]. eNOS has also been observed in the lungs and trachea where it modulates ciliary motility and smooth muscle relaxation [7]. Neuronal NOS (nNOS) is localized primarily in the brain and central nervous system (CNS). The NO produced by this isoform is used for neurogenesis and regulation of the cholinergic, dopaminergic and glutaminergic signalling pathways, among others [8]. The final isoform, inducible nitric oxide synthase (iNOS), produces NO in response to infection of host cells by bacteria or other pathogens. This NO has been observed to have both pro and antiinflammatory effects and also some tumour suppression activity [9].

All three isoforms exist as homodimeric enzymes, with each monomer consisting of an N-terminal oxygenase domain and a C-terminal reductase domain [10]. These domains are connected by a calmodulin binding region (CBR). The oxygenase domain contains a non-catalytic zinc, tetrahydrobiopterin $\left(\mathrm{BH}_{4}\right)$ and the catalytic active site, which binds L-arginine and a heme moiety. The reductase domain employs nicotinamide adenine dinucleotide phosphate (NADPH), flavin adenine dinucleotide (FAD) and flavin mononucleotide (FMN) to shuttle electrons from the reductase domain to the iron at the centre of the heme co-factor in the catalytic active site [6]. In the active site, L-arginine then 


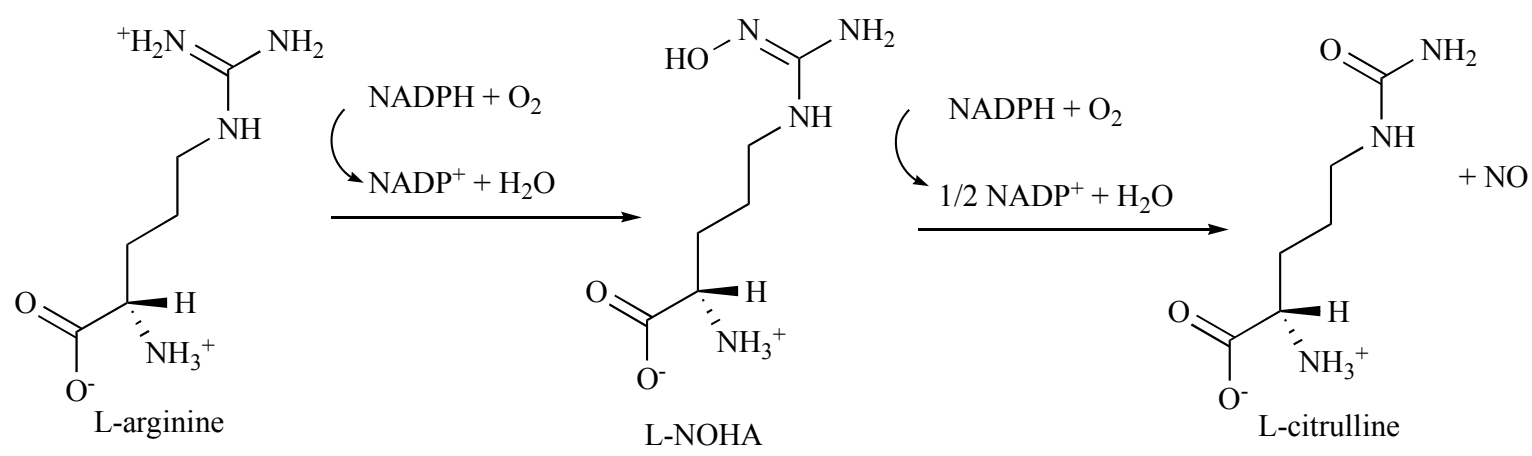

Fig. (1). Production of NO from L-arginine and molecular oxygen.

becomes oxidised to L-citrulline and NO is produced [11]. The zinc ion in the oxygenase domain, while not directly participating in the catalytic cycle, provides a coordination site for four symmetry related cysteine residues, two from each monomer. This tetrahedral coordination sphere is an integral part of the dimer interface of NOS enzymes [12-14].

Activation of eNOS and nNOS is dependent on calmodulin (CaM) binding [15]. This binding event is controlled by calcium levels where an increase in cellular calcium concentration facilitates formation of the NOS/CaM complex. Without CaM the enzymes are far less efficient at electron transfer and activity notably decreases [16]. This system offers a regulatory mechanism for the constitutively expressed eNOS and nNOS. In contrast, $\mathrm{CaM}$ is bound to iNOS, even at low calcium concentrations, and as this isoform is inducibly expressed, it is regulated at the transcriptional level [17].

The mechanism of NO production is conserved across all three isoforms with the heme iron in the arginine binding site playing a central role in the catalytic cycle. Although some of the specifics of this pathway have yet to be elucidated, a proposed cycle is provided below, adapted from the literature [17-19]. The exact nature of the oxidative species is still unclear [18].

The proposed cycle begins with the heme iron in the resting (III) oxidation state. An electron, transferred from the reductase domain, reduces the heme iron to the (II) oxidation state. Molecular oxygen binds to the iron and subsequent electron transfer from $\mathrm{BH}_{4}$ and protonation generates an iron peroxy complex. Protonation, electron transfer (from the porphyrin (Por) ring) and loss of water generates the iron (IV) complex with a doubly bound oxygen atom $[15,18]$. The iron (IV) complex then reacts with L -arginine to form the intermediate L-NOHA and iron (III) is regenerated. A similar sequence of steps is then repeated, starting with the transfer of an electron from the reductase domain, reducing the heme iron to the (II) oxidation state. The reaction sequence changes once the iron (III) peroxy species is generated, which reacts with L-NOHA to produce L-citrulline and an iron (III) nitrosyl species. In the final steps, the NO radical is formed and released along with the regeneration of iron (III) and the cycle begins again.

\subsection{NOS and Disease}

Uncoupling of the NOS electron transport chain, or overproduction of NO by the NOS enzymes, has been linked to a wide variety of neurological and physiological disorders $[20,21]$. In the absence of $\mathrm{BH}_{4}$ the NOS electron transport chain becomes uncoupled, which results in the production of ROS such as superoxide, $\mathrm{O}_{2}{ }^{-}$. This superoxide can further react to generate reactive nitrogen species (RNS), such as peroxynitrite $\left(\mathrm{ONOO}^{-}\right)[11,19,22]$. Both of these species can inflict oxidative stress on cells, resulting in translation errors and protein aggregation. This may occur with any of the NOS isoforms. In situations where the NOS enzyme is overly active, these oxidative stress events happen more rapidly resulting in accelerated cellular damage.

Oxidative damage caused by iNOS generated NO has been linked to auto immune and inflammatory disorders including rheumatoid arthritis [23]. Excessive NO production by iNOS is also a contributory factor in the onset of septic shock [9]. Over active nNOS can result in hyperphosphorlyation and accumulation of tau proteins, an event which has been implicated in Alzheimer's disease [24,25]. In addition oxidative damage caused by over active nNOS leads to dysregulation of the signalling pathways and has long been associated with a variety of neurological conditions including Parkinson's disease [26,27]. Elevated levels of NO metabolites have also been observed in the brain tissue of schizophrenic patients [28]. eNOS has not been directly identified as a "disease gene", however oxidative damage potentially caused by overactive eNOS has been observed in a range of cardiovascular diseases [29].

\subsection{NOS Binding Pockets and Ligand Design}

Partial inhibition of overactive NOS enzymes may slow the production of damaging ROS and RNS and prevent the build-up of potentially harmful levels of NO. To date several families of small molecule inhibitors have been developed for this purpose. These inhibitors have been targeted at four potential therapeutic target sites of the NOS enzymes. These are:

1. The $\mathrm{BH}_{4}$ site, located in the oxygenase domain, which binds the co-factor $\mathrm{BH}_{4}$.

2. The CaM binding site, which sits between the oxygenase and reductase domains.

3. The NADPH binding site, which is located in the reductase domain.

4. The catalytic active site, which is located in the oxygenase domain and binds arginine for production of NO. 
These four sites have been exploited for the design of selective nNOS ligands using structure based drug design (SBDD) and ligand based drug design (LBDD) approaches. SBDD encompasses the use of techniques such as molecular docking to predict protein-ligand [30] interactions, and de novo design of novel compounds. In contrast, LBDD focuses on available ligand based experimental information and includes techniques such as pharmacophore design and quantitative structure activity relationship (QSAR) approaches [31]. Both SBDD and LBDD have resulted in some notable successes in nNOS inhibitor development with hit compounds displaying good levels of activity and selectivity. The pharmacokinetics (PK) properties and blood brain barrier (BBB) penetration of nNOS inhibitors is also of critical importance. The hit to lead process often focuses on examining the PK properties of a hit compound and employs computational and medicinal chemistry techniques that result in compounds with lower molecular weights, lower numbers of hydrogen bond (HB) donors/acceptors and increased lipophilicity. Some nNOS inhibitors which have shown promising efficacy and selectivity have undergone structural modifications in order to improve their PK properties and make them more attractive for clinical use.
Previous reviews in this area have focused on the medicinal chemistry and SAR development of inhibitors for the three NOS isoforms [32,33]. This review will discuss the classes of inhibitors developed for each of the four nNOS therapeutic target sites, their potential interactions with the target site and the role computer aided drug design has played in the process of selective nNOS inhibition. The PK properties of some of the most efficacious nNOS inhibitors will also be examined.

\section{NOS BINDING SITES}

\section{1. $\mathrm{BH}_{4}$ Binding Site}

Tetrahydrobiopterin, $\mathrm{BH}_{4}$ (Fig. 3), is a pterin ring containing prosthetic group which is crucial for NOS function. It participates in electron transfer during NO production, (Fig. 2), and also plays a role in NOS dimer formation and stabilisation, which is necessary for enzyme activation [34].

Owing to the importance of the $\mathrm{BH}_{4}$ binding site in NOS enzymes, efforts have been made to target it using various substituted pterins. Matter et al. developed a series of $654-$ amino pteridine and 4-oxo pteridines, and examined their inhibitory effects on recombinantly produced NOS protein [35-37].

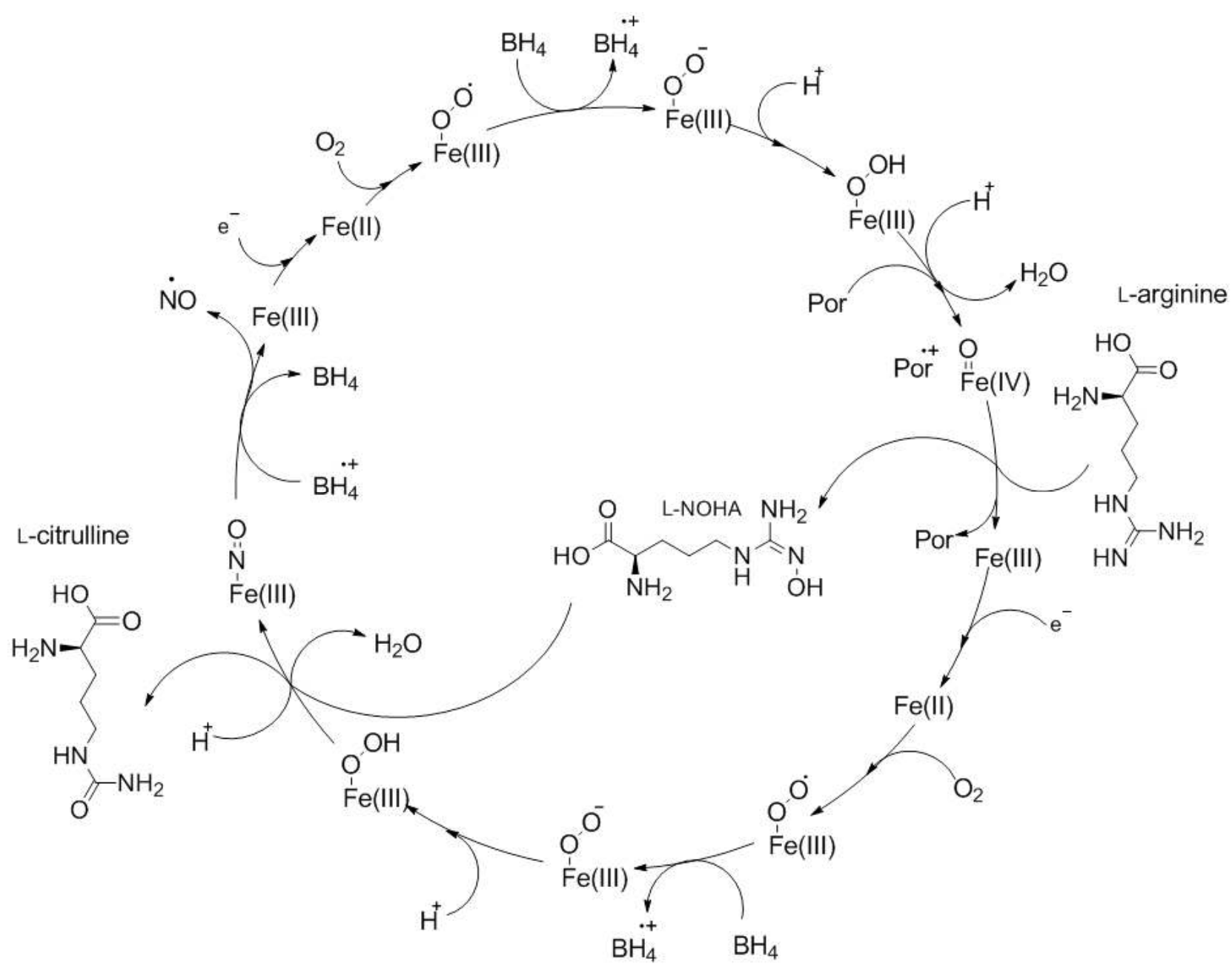

Fig. (2). Proposed NOS catalytic cycle (where Por=porphyrin). 
<smiles>C[C@H](O)[C@@H](O)[C@H]1CNc2[nH]c(N)nc(=O)c2N1</smiles>

Fig. (3). Tetrahydrobiopterin.

In the absence, at the time, of any experimentally derived protein crystal structure for nNOS, Matter et al. made use of homology modelling to rationally develop these 65 inhibitors. Murine iNOS and bovine eNOS [14,38] crystal structures were used as templates with a sequence homology to human $\mathrm{nNOS}$ of $52.19 \%$ and $57.34 \%$ respectively. Utilising their human nNOS homology model, Matter et al. [36] developed 3D-QSAR models, and performed comparative molecular field analysis (CoMFA) and comparative molecular similarity index analysis (CoMSIA) to correlate molecular property fields to biological activities. The models were developed to provide guidelines and activity predictions for novel nNOS inhibitors. The preferred model identified one large sterically favourable region matching with the requirement for pterin binding. A series of the predicted inhibitors were synthesised and tested.

One of the most efficacious and selective compounds to result from this study was compound 1 (Fig. 4) Compound 1 [36] had $\mathrm{IC}_{50}$ values of $5 \mu \mathrm{M}, 214.2 \mu \mathrm{M}$ and $31.7 \mu \mathrm{M}$ for porcine nNOS, bovine eNOS and human iNOS, respectively. It was suggested that this selectivity was based on a one residue difference between the isoforms. In eNOS residue 106 is a Val, whereas iNOS and nNOS contain Met in the equivalent position. The added steric bulk of the valine residue in eNOS may make binding of compound $\mathbf{1}$ to eNOS less favourable than binding to either iNOS or nNOS. No explanation was provided in this initial publication regarding compound selectivity for nNOS over iNOS.

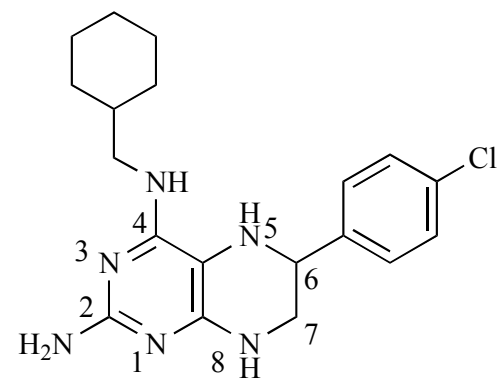

Fig. (4). Selective nNOS inhibitor, compound 1 [36].

In a subsequent publication, Matter et al. [37] presented the key interactions for $\mathrm{BH}_{4}$ in the crystallised rat nNOS $\mathrm{BH}_{4}$ binding site (Fig. 5). The strongest interaction for $\mathrm{BH}_{4}$ was determined to occur with a tryptophan, Trp678. A $\pi-\pi$ interaction was observed between this residue and $\mathrm{BH}_{4}$ at a distance of 3.6 ̊. An extensive network of HB interactions was also identified. N-3 of $\mathrm{BH}_{4}$ forms a direct $\mathrm{HB}$ with the carboxylate of the heme moiety and a solvent mediated interaction also exists between the same propionate group and the C-4 carbonyl. This carbonyl group directly HBs with Arg596. The primary amine at C-2 interacts with the heme propionate and HBs with Trp678. Matter et al. described the
N-8 hydrogen interacting with Val677 and the $\mathrm{BH}_{4}$ dihydroxypropyl chain extending into the pocket formed by side chains of TrpB306, Met336 and TrpB676. The dihydroxypropyl chain also interacts with Ser334 and PheB691 carbonyl oxygens and with HisB692 via structural water.

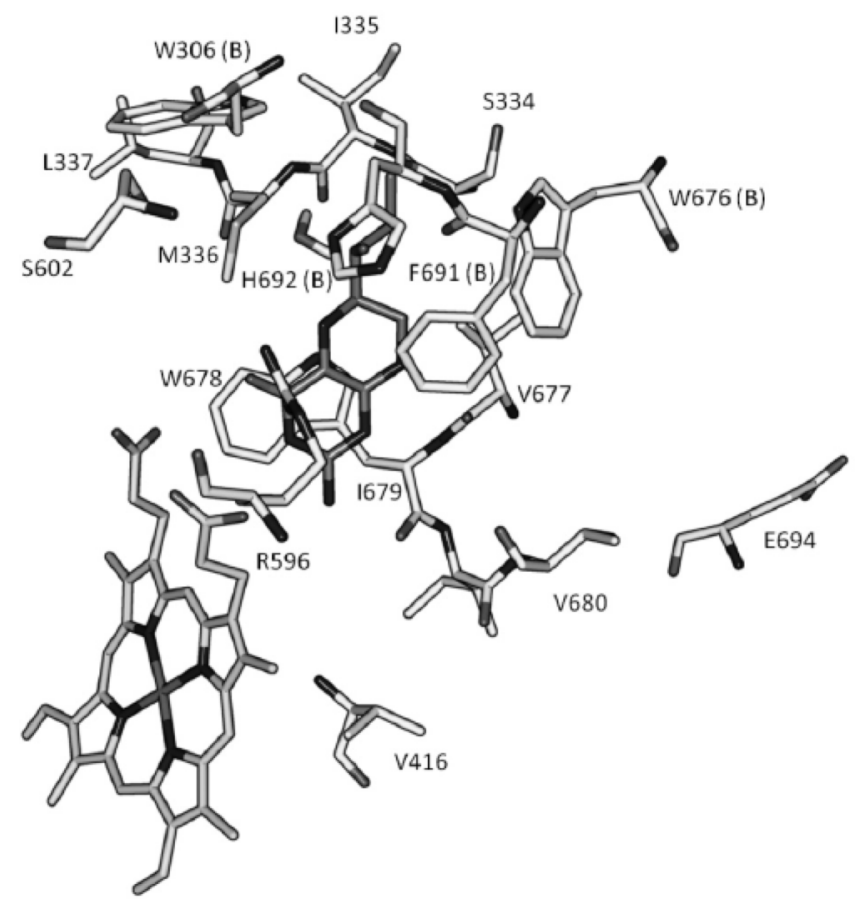

Fig. (5). Rat nNOS $\mathrm{BH}_{4}$ binding site key residues (PDB: 4D2Y) with $\mathrm{BH}_{4}$ and heme. The structural water which mediates the dihydroxypropyl interaction with HisB692 has been included [37]. All images generated with Pymol [39].

With a clear and detailed knowledge of the key interactions within the binding site, the group refined their previous inhibitor family and devised four key scaffolds (A1, A2, T1 and T2), which attempted to mimic the interactions of $\mathrm{BH}_{4}$ with the nNOS binding site (Fig. 6) [37].

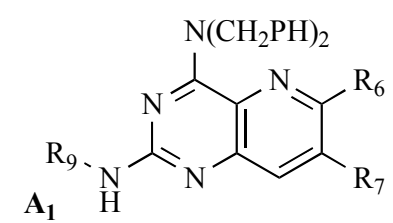<smiles>[R9]Nc1nc2cc([R7])c([R2])nc2c(=O)[nH]1</smiles><smiles>[R]Nc1nc([R1])c2c(n1)NC([R7])C([R6])N2[R8]</smiles><smiles>[R]Nc1nc2c(c(=O)[nH]1)N([R3])C([R6])[C@@H]([R6])N2</smiles>

Fig. (6). Refined inhibitor scaffolds based on $\mathrm{BH}_{4}$ interactions with the rat nNOS binding site [37].

A variety of compounds were developed based on these scaffolds which showed an array of selectivities and potencies against nNOS [37]. The assay work was conducted using the human nNOS isoform. Once again compound 1 (Fig. 4) proved to be both efficacious against, and selective 
for, human $\mathrm{nNOS}$. The $\mathrm{IC}_{50}$ for this compound against human nNOS was $3.68 \mu \mathrm{M}$ with a 58.20 and 8.62 fold, selectivity over human iNOS and human eNOS, respectively. Compound 1 was a member of the T1 scaffold family shown above (Fig. 6).

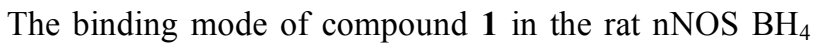
site was predicted using docking [37]. The key predicted interactions for compound $\mathbf{1}$ were similar to the X-ray validated interactions of $\mathrm{BH}_{4}$ with the rat nNOS binding site. The primary amine group HBs to the heme carboxylate and also to the Trp678 residue. The hydrogen on N-8 interacts with Val677. The C-4 carbonyl of $\mathrm{BH}_{4}$ is replaced by a C-4 $\mathrm{NH}$, which breaks the HB interaction with Arg596. The large p-chlorophenyl group is accommodated by a pocket formed by TrpB306, Met336 TrpB676 and Glu694 (Fig. 5). This pocket plays a key role in the selectivity of compound $\mathbf{1}$ for nNOS over eNOS and iNOS. Replacement of Met336 with a valine (as in eNOS) resulted in lower binding affinity as previously suggested by Matter et al. [36].

The basis for NOS selectivity of the A1, A2, T1 and T2 scaffolds (Fig. 6) was further explored and three key substituent groups were identified as having an impact on compound selectivity [37]. These were:

1. Bulky, hydrophobic substituents at R2 or R3 increased selectivity for nNOS over eNOS and iNOS on scaffold $\mathbf{T 1}$ and $\mathbf{T} 2$

2. Substituted amines at R1 (scaffold A1 and T1), are preferred over oxo groups (scaffold A2 and T2)

3. Hydrophobic electron rich groups at R3 increased binding for all scaffolds

The work of Matter et al. established the $\mathrm{BH}_{4}$ binding site as a validated target site for selective nNOS inhibition. However, much of the subsequent literature has focused on other NOS binding sites.

\subsection{Calmodulin Binding Site}

$\mathrm{CaM}$ binding to NOS enzymes is an integral part of their function. The calmodulin binding region (CBR) of the enzymes is a $\sim 25$ amino acid sequence located between the oxygenase and reductase domain [40]. CaM binding allows a $70 \AA$ conformational change to occur in the NOS proteins, as determined by NMR spectroscopy and hydrogen deuterium exchange mass spectrometry $[41,42]$. This conformational change facilitates the transfer of an electron from the final reductase partner, FMN, to the heme moiety in the oxygenase domain of another NOS monomer as illustrated in the schematic (Fig. 7) [16].

The interaction between the NOS proteins and CaM has been explored using crystallography and computational studies. Human eNOS binds to CaM using the classical 1-5-8-14 motif $[43,44]$ with Phe496, Ala500, Val503 and Leu509 of eNOS forming critical interactions with CaM [45]. The alignment of the three NOS calmodulin binding domains is shown below, with the 1-5-8-14 residue highlighted in each sequence (Table 1). The 1-5-8-14 residue motif is conserved precisely in human nNOS and eNOS, while there are two residue changes in the iNOS motif. The iNOS sequence contains more hydrophobic residues than either of the constitutive isoforms, which may explain the higher affinity of iNOS for CaM [45].

These CBRs of the NOS proteins have been suggested as a possible therapeutic target site for NOS inhibition [40,4648]. The residue differences between the nNOS CBR and the eNOS and iNOS CBR may make selective nNOS inhibition of this site possible. There are two principle strategies focused on CaM. The first is to design molecules that bind to $\mathrm{CaM}$ itself and prevent it binding to its recognition site on the NOS proteins. Some of the compounds tested for this purpose include the wasp venom peptide mastoparan, the bee venom peptide melittin and monobutyltin trichloride (com-

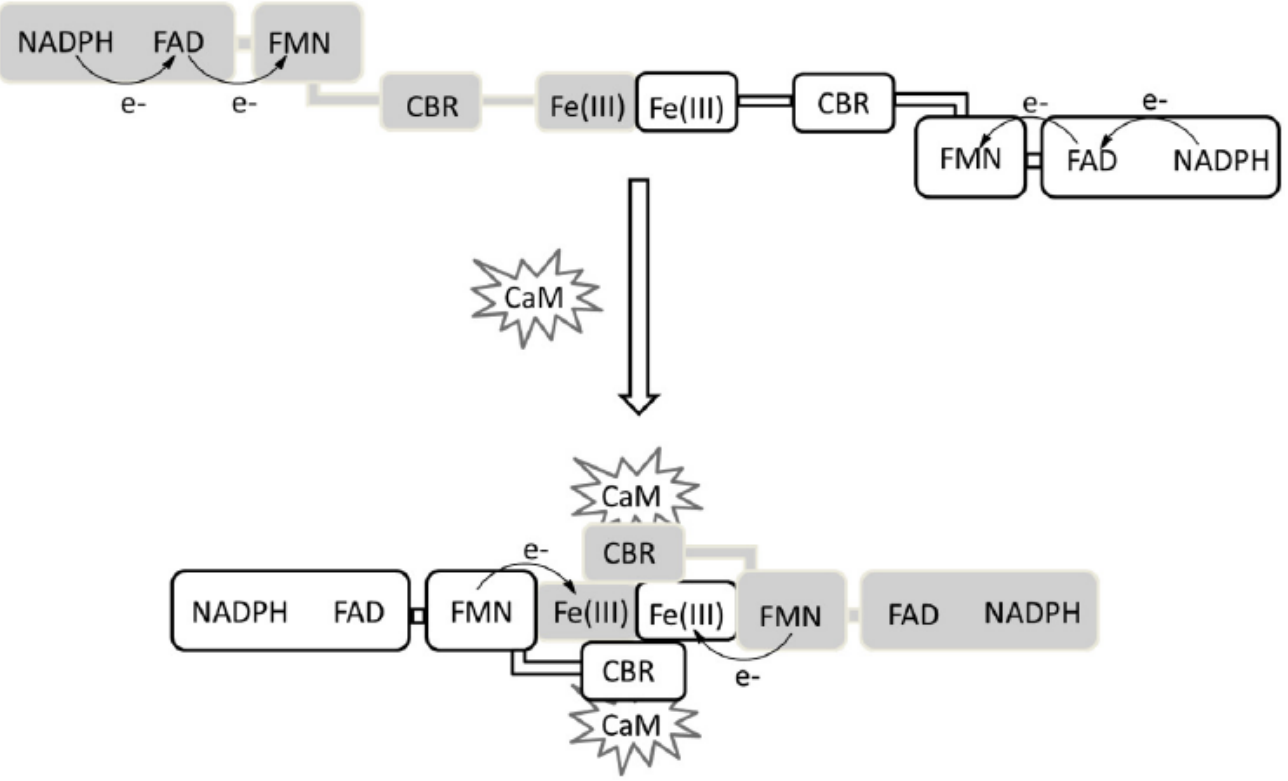

Fig. (7). CaM mediated hinge of NOS proteins. The NOS protein is shown in its dimer form, with one monomer in grey and the other in white. 
pound 2, Fig. 8) [40]. These compounds were observed to decrease the levels of CaM available to nNOS in an isolated system, with $\mathrm{K}_{\mathrm{i}}$ values of $5 \mathrm{nM}, 3 \mathrm{nM}$ and $8 \mu \mathrm{M}$ for CaM respectively. However, this method of NOS inhibition is not selective for nNOS as the compounds bind to CaM and not to the NOS enzymes themselves.

Table 1. CaM binding regions of the human NOS isoforms with the 1-5-8-14 motif highlighted in bold.

\begin{tabular}{|c|c|}
\hline Isoform (Residues) & Alignment \\
\hline \hline Human iNOS (412-431) & REIPLKVLVKAVLFACMLMR \\
\hline Human eNOS (493-512) & RKKTFKEVANAVKISASLMG \\
\hline Human nNOS (732-751) & RAIGFKKLAEAVKFSAKLMG \\
\hline
\end{tabular}<smiles>CCCC[Sn](Cl)(Cl)Cl</smiles>

Fig. (8). Monobutyltin trichloride, compound 2 and Tamoxifen, compound $\mathbf{3}$.

An alternative approach is to design an inhibitor which competitively binds to the CBR of the NOS proteins, thus preventing CaM binding. This method may be more favourable as it offers the possibility of selective nNOS inhibition and would also avoid interfering with other CaM signalling pathways not related to NOS. These pathways include many vital physiological functions such as muscle contractions, and therefore non-specific CaM inhibition may not be clinically desirable. The breast cancer treatment Tamoxifen (compound 3, Fig. 8) was found to bind to the nNOS CBR with a reduction in enzyme activity in the range of $10-30 \%$ observed [40]. No selectivity data was presented in this publication.

Some studies have also been conducted on NOS CaM inhibition using synthetic peptides which were 19-28 residues in length. These sequences were not computationally designed but were observed to bind to the eNOS CBR and prevented CaM from interacting with the eNOS enzyme, thus inhibiting NO production. [49] Other non-computationally derived compounds used to inhibit NOS/CaM interaction include compound 4 (Fig. 9) which was reported to have an $\mathrm{IC}_{50}$ of $1.99 \mu \mathrm{M}$ against the $\mathrm{CaM}$ site of recombinant rat nNOS [50].

The CBR of nNOS has not been as extensively studied as other pockets such as the arginine binding site for nNOS inhibition. One of the key challenges associated with targeting the CBR region of nNOS is generating significant isoform selectivity. In addition, the design of compounds to disrupt protein-protein interactions is also inherently difficult no matter what the target [51].

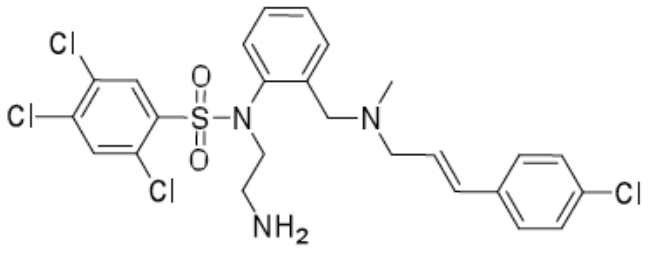

Fig. (9). Competitive CaM inhibitor, compound 4 [50].

\subsection{NADPH Binding Site}

NOS catalysis is driven by the reduction of NADPH, which binds to the reductase domain of NOS enzymes. The NADPH binding site therefore offers a potential intervention point at which the NOS catalytic cycle could be halted, thus inhibiting enzyme activity. Beaumont et al. [52] developed a nanotrigger, NT1, to monitor enzymatic activity at this site. NT1 contains a conjugated, photoactivatable chromophore substituted with two donor groups that replaced the nicotinamide moiety of NADPH (Fig. 10) [52-54]. This compound has the ability to initiate the redox reaction, triggered by a short laser pulse, leading to enzymatic activity with redox reaction. Subsequently, Beaumont et al. [54] assessed the selective binding of NT1 to nNOS using fluorescence measurements and molecular modelling. Molecular dynamic (MD) simulations revealed that the regulatory Phe1395 (rat nNOS) flipped away from FAD upon NT1 binding, bringing NT1 and FAD into close proximity. A number of HBs stabilised the NT1 interaction, including those between the terminal phosphate group and Arg1400, Arg1314, and Arg1284. The amide carbonyl oxygen formed a HB with Arg1010, while the terminal amino group interacted with Asp1393 and Ser1176. The authors proposed the use of NT1 for time resolved X-ray and other cellular applications including the design of specific activators or inhibitors of enzymatic activities.

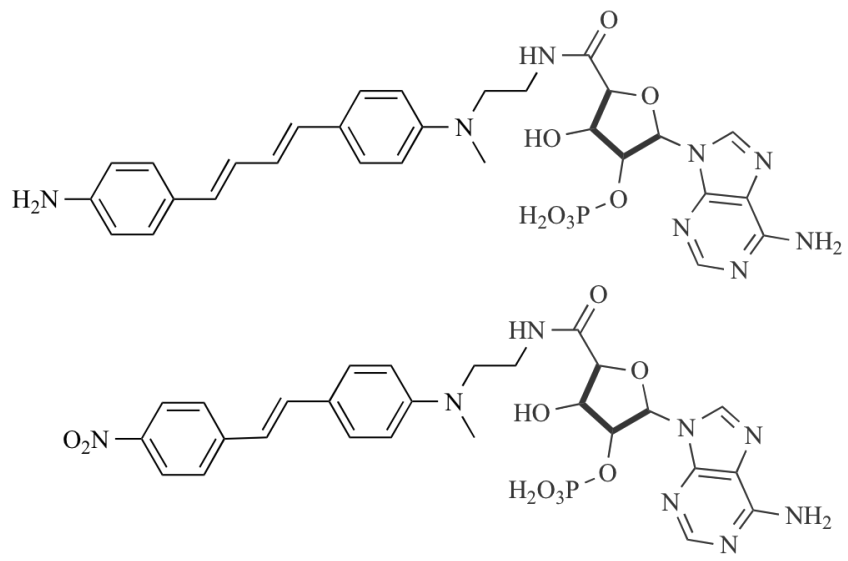

Fig. (10). Nanotrigger NT1 [52] and nanoshutter NS1 [55], compound 5 and $\mathbf{6}$. The structural motif on the right of the image binds to the NADPH site in NOS proteins, while the left portion of the compound acts as the chromophore.

Subsequently, Li et al. [55] examined the use of a nanoshutter, NS1, (Fig. 10) which also targets the NADPH site of nNOS. Here a nucleotide moiety, mimicking NADPH, is linked to a conjugated push-pull chromophore with non- 
linear absorption properties. The development of NS1 was guided by molecular modelling studies which replaced the 1,4-diaryl-butadiene moiety of NT1 with a stilbene moiety [55]. The authors proposed that employing a nitro group as the terminal electron acceptor would block electron flow and hence inhibit NOS activity. NS1 did indeed inhibit NOS activity and was shown, using molecular docking and $10 \mathrm{~ns}$ MD simulations, to fit into the narrow NADPH site of nNOS. The key interactions across the simulation again involved the conserved Arg residues (Arg1400, Arg1314, Arg1284, Arg1010) in the NADPH binding site. NS1 represents a new class of NOS inhibitor and, as a fluorescent compound with 2-photon excitation properties, NS1 has potential for use in NOS imaging in living tissues when bound to constitutive eNOS or nNOS.

\subsection{Arginine Binding Site}

\subsubsection{Guanidinium Containing Inhibitors}

A large portion of contemporary literature in the area of nNOS inhibition has focused on arginine analogues $[32,56,57]$. These compounds act as competitive inhibitors of the NOS isoforms by mimicking the interactions of the enzyme's natural substrate. One of the first compounds developed in this area was $N^{\omega}$-nitro-L-arginine (L-NNA) Fig. (11).<smiles>N=C(NCCC[C@H](N)C(=O)O)N[N+](=O)[O-]</smiles>

Fig. (11). L-NNA (Compound 7), one of the earliest arginine mimics studied for NOS inhibition [58].

L-NNA has a potent effect on eNOS resulting in severe hypertension and hence a number of derivatives based on LNNA were developed in order to improve selectivity for nNOS [59]. Modifications included replacing the carboxylic acid functionality with a methyl ester and substitution of the nitro group for a methyl group. However, these compounds continue to suffer from poor isoform selectivity and have pharmacokinetic properties which make them unattractive as potential therapeutics [60].

In an attempt to improve the potential of the L-NNA class of NOS inhibitors, the precise binding mode of L-NNA with bovine eNOS was deduced via crystallization in 2001 [61]. It was observed that L-NNA retained the same HB pattern as the natural substrate, L-arginine, with HBs forming between the Glu363 and the guanidinium moiety and between the $\alpha$ amino group on the inhibitor and the heme propionate in the binding site. Thirteen non bonded interactions were observed between L-NNA and the binding site, all involving the nitro group and Pro336, Phe355, Ser356 and Gly357 (Fig. 12). The eNOS inhibition studies were the first step towards understanding the key binding elements necessary for selective nNOS inhibition using the L-NNA family of inhibitors.

The vast majority of subsequent nNOS inhibition studies have been conducted using the rat isoform of nNOS [62,63] or on a homology model of the human nNOS based on the rat nNOS structure [37,64]. The crystal structure showing the binding mode of the natural substrate, arginine, with rat
nNOS was elucidated in 2003 (PDB code 1OM4, unpublished article) along with the binding modes of arginine like inhibitors in rat nNOS. (PDB code 1K2R, unpublished article). This represented a significant advance in the field of NOS inhibition as, for the first time detailed information describing the rat nNOS ligand binding pocket was available. An image of this arginine binding site, with L-NNA bound, is provided in Fig. (13).

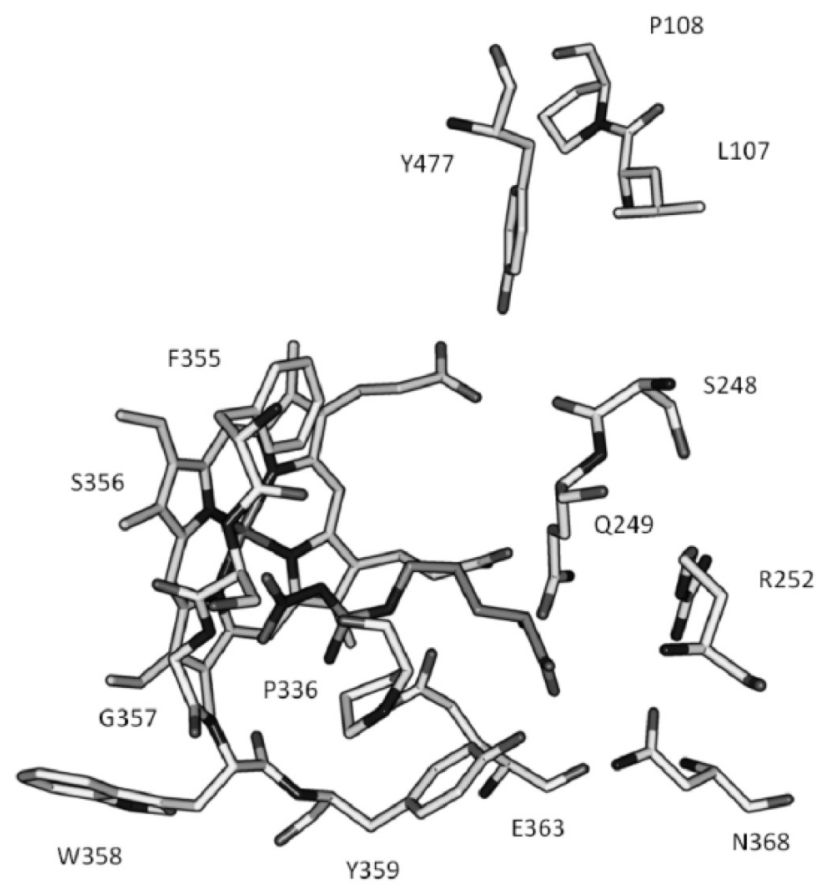

Fig. (12). Bovine eNOS with L-NNA (compound 7) bound with heme and the ligand. (PDB:8NSE) [61].

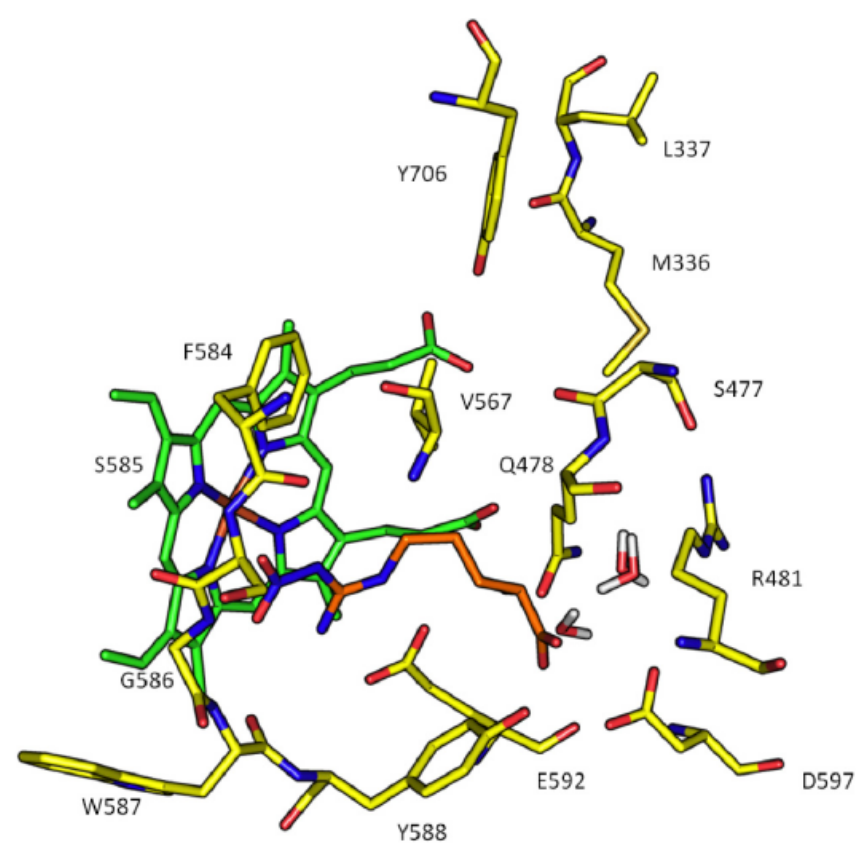

Fig. (13). Rat nNOS arginine binding site with the L-NNA (compound 7) bound (PDB: 1K2R). Waters involved in solvent mediated interactions between Asp597 and L-NNA have been included. $\mathrm{BH}_{4}$ has been omitted for clarity. 
Glu592 (Glu363 in bovine eNOS) was observed to form several HB interactions with the nitro guanidino group of the L-NNA inhibitor. Asp597 was also involved in binding via water mediated electrostatic interactions with the primary $\alpha$ amino group of the inhibitor. The $\mathrm{C}$ terminal carboxyl group of L-NNA undergoes HB with Gln478, Arg481 and Ser477 while the side chain amino group interacts via a water molecule with the heme propionate [65].

The availability of both bovine eNOS and rat nNOS crystal structures allowed for detailed selectivity studies of the LNNA based inhibitors. Flinspach et al. [65] observed $\mathrm{K}_{\mathrm{i}}$ values of $0.13 \mu \mathrm{M}, 0.12 \mu \mathrm{M}$ and $0.07 \mu \mathrm{M}$ for rat $\mathrm{nNOS}$ for compounds 8, 9 and 10 respectively (Fig. 14). These same compounds had $\mathrm{K}_{\mathrm{i}}$ values of $200 \mu \mathrm{M}, 300 \mu \mathrm{M}$ and $130 \mu \mathrm{M}$ respectively for bovine eNOS.

In the rat nNOS binding site, the inhibitors bound in a manner similar to that observed for L-NNA. The guanidine mimic made a bifurcated HB with Glu592. The nitro group of the inhibitors made an additional $\mathrm{HB}$ with the protein backbone, strengthening the interaction of the inhibitors with the binding site. In bovine eNOS the in- hibitors make the same interactions with the equivalent glutamic acid, Glu363. In eNOS, either the guanidine to glutamate bond, or the nitro to backbone HB is stretched slightly $(\sim 3.2 \AA)$ which partly explains the selectivity of the compounds. The most important difference between eNOS and nNOS however was thought to be the replacement of Asp597 in nNOS with Asn368 in eNOS. It was hypothesised that the presence of the negatively charged residue in nNOS encouraged the inhibitors to adopt a curled configuration. This allowed the $\alpha$ amino group on the inhibitors to be stabilised by both Asp597 and Glu592 in nNOS. In eNOS, this dual stabilisation was not possible as the aspartic acid was replaced by an asparagine [65]. The extended binding conformation of compound $\mathbf{1 0}$ in eNOS and its curled binding conformation in nNOS are shown in Fig. (15).

Building on these observations Ji et al. made use of compound 10 and molecular interaction field (MIF) analysis to examine the binding sites of rat nNOS, bovine eNOS and human iNOS [66]. Probes covering hydrophobic, steric and HBA/HBD interactions were used to calculate MIFs in the
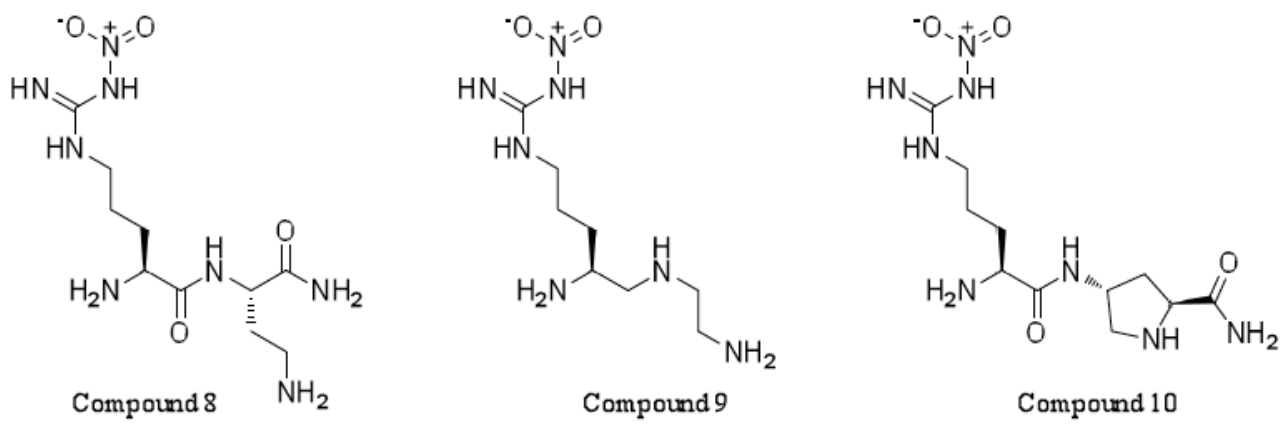

Fig. (14). Compounds 8, 9 and 10 used by Flinspach et al. to examine the basis of selectivity between nNOS and eNOS [65].

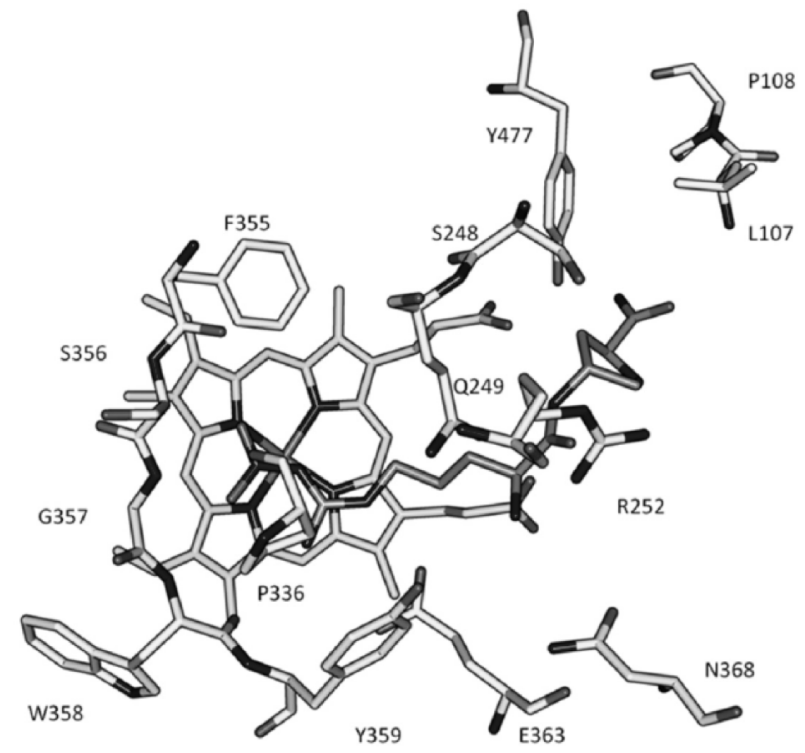

Bovine eNOS, extended conformation

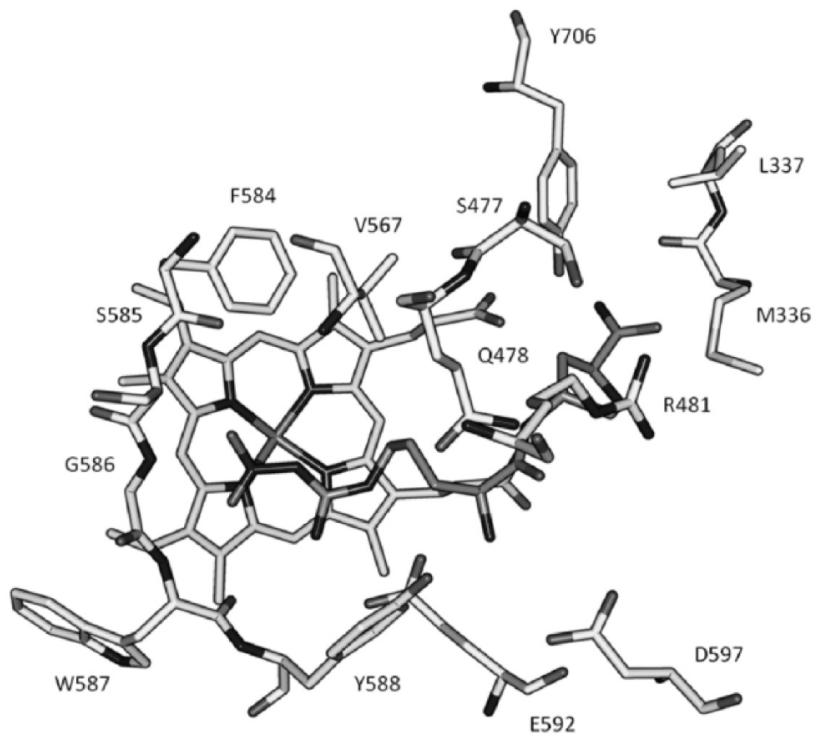

Rat nNOS, curled conformation

Fig. (15). Bovine eNOS with compound 10 bound in extended conformation (PDB: 1P6N) vs rat nNOS with compound 10 bound in curled conformation (PDB:1P6J). Notice the proximity of the primary amine of the inhibitor to E592 in rat nNOS (2.8 $\AA$ ), while the equivalent primary amine is further removed from E363 in bovine eNOS (5 А) [65]. 
active sites of the three NOS isoforms. The most important determinants for rat nNOS selectivity were identified as hydrophobic and charge-charge interactions [66].

Binding modes were explored by flexibly docking 25 known NOS inhibitors (including the dipeptides shown in Fig. 14) into the binding site of the three NOS isoforms using AutoDock3 [67]. The combined GRID [68]/CPCA (consensus principal component analysis) and docking approach identified regions important for selectivity and yielded insights into important protein-ligand interactions [66]. Four pockets were identified, termed the $\mathrm{S}, \mathrm{M}, \mathrm{C} 1$ and $\mathrm{C} 2$ pockets (see Fig. 16). In rat nNOS the $S$ pocket is found above the heme ring and is comprised of residues Phe584, Val567 and Pro565. The M pocket is located between the substrate catalytic site and the substrate access channel. This pocket includes the residues Asp597, Ser477, Ser568, Gln478, Arg481, Asn569 and Arg603. The $\mathrm{C} 1$ and $\mathrm{C} 2$ pockets are a little removed from the substrate binding cavity and constitute the substrate access channel. The $\mathrm{C} 1$ pocket contains Met336, L337, Glu307, Asn601 and Ser602 while the C2 pocket contains Pro708, Asp709, Pro710 and Gln500.

The S pocket (with the exception of the Asn370Ser difference in iNOS) is identical in the three NOS isoforms used in this study, (rat nNOS, bovine eNOS and human iNOS). As such, it is difficult to explain the selectivity exhibited by some L-arginine analogues when only considering binding in the $\mathrm{S}$ pocket.

From the analysis of several probes, e.g. DRY (hydrophobic probe) and $\mathrm{N} 1+$ (charged probe), a ligand with a hydrophobic functional group interacting at the $M$ pocket was proposed to improve selectivity towards human iNOS. The $M$ pocket is defined by residues Ser477 and Ser568 in rat nNOS or Ala262 and Ala353 in human iNOS, which are postulated as being responsible for selectivity between the two isoforms. Alternatively, introduction of a positively charged functional group would be unfavourable for eNOS binding in the $\mathrm{M}$ pocket. The nNOS $\mathrm{M}$ pocket is a more negative environment than the eNOS $M$ pocket, with rat nNOS residue Asp597 being replaced by Asn368 in the bovine eNOS M pocket. This highlighted the significance of the $\mathrm{M}$ pocket in the design of isoform selective ligands.

The $\mathrm{C} 1$ pocket differs among the NOS isoforms (rat nNOS, bovine eNOS and human iNOS) at five residues. Two selective regions were found, the first at residues Met336 and Leu337 of rat nNOS and another at residues Glu307, Asn601 and Ser602 of rat nNOS. A histidine residue, His342 in human nNOS, (equivalent to Met336 in rat nNOS) could potentially be used to guide selective ligand design.

There are four residues in the $\mathrm{C} 2$ pocket that differ across the NOS isoforms (rat nNOS, bovine eNOS and human iNOS). The most important residues determined for selectivity are at the rat nNOS Asp709/human iNOS Glu494 positions. The authors postulated that inhibitors with a positively charged functional group positioned near the Asp709 of rat nNOS should be selective towards nNOS [66].

\subsubsection{2-Aminopyridine containing inhibitors}

The 2-aminopyridine class of NOS inhibitors target the arginine binding pocket and as their name suggests contain both a pyridine and amine functionality. It had been previously observed, prior to the elucidation of the rat nNOS crystal structure, that 2-aminopyridines (compound 11) [69] and quinazolines (compound 12) [70] were inhibitors of NOS (Fig. 17)

The recent in silico driven era of NOS inhibitor development attempted to build on these known inhibitor scaffolds with Garcin et al. employing an anchored plasticity approach [71]. The known binding mode of the 2aminopyridine and the quinazoline was conserved in the ar-

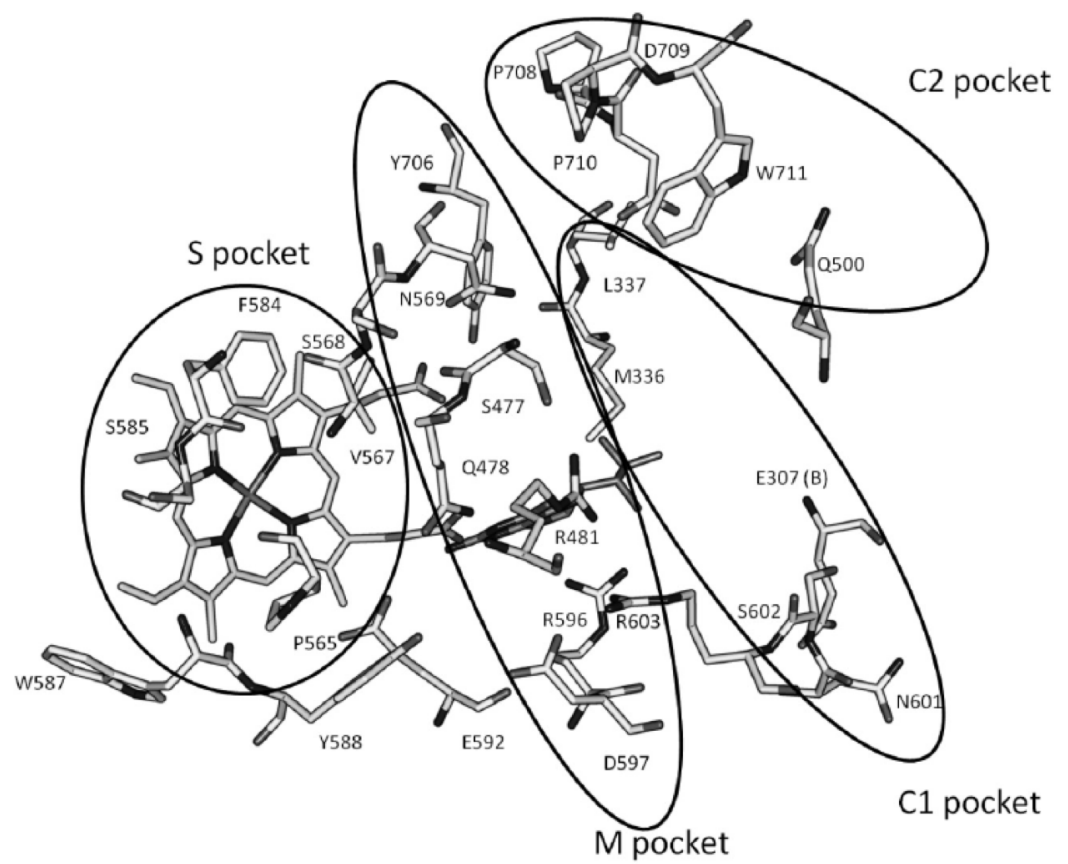

Fig. (16). Binding pockets of the rat nNOS arginine active site as defined by Ji et al. [66] with L-NNA bound (compound 7), (PDB:1K2R). 
ginine binding site, and various substituents were attached to the inhibitor scaffolds in an attempt to improve inhibitor efficacy and selectivity. It was envisaged that the known scaffold would maintain inhibitor binding, while the various substituents would allow the inhibitor to interact with other parts of the arginine binding site. Of particular interest were those areas of the binding site that contained residues which were not conserved across the three isoforms and which could be exploited so as to improve inhibitor selectivity. Using this method, Garcin et al. developed a novel series of NOS inhibitors [71] with one of the most efficacious compounds being the human iNOS inhibitor shown in Fig. (18) (Compound 13).<smiles>Cc1ccnc(N)c1</smiles>

Compound 11<smiles>NC1=NC(c2ccco2)Nc2c(F)ccc(F)c21</smiles>

Compound 12
Fig. (17). 2-Aminopyridine (compound 11) and quinazoline (compound 12) NOS inhibitors [69,70].<smiles>COc1ccnc(NC2CCN(C(=O)c3ccc(C#N)cc3)CC2)c1</smiles>

Fig. (18). iNOS selective inhibitor, compound 13, derived from anchored plasticity studies. This compound has an iNOS $\mathrm{IC}_{50}$ of $0.074 \mu \mathrm{M}$ with a 100 fold eNOS selectivity and 6 fold nNOS selectivity [71].

Protein crystallization studies of compound $\mathbf{1 3}$ (and other similar compounds) with human iNOS revealed that binding did indeed occur at the arginine binding site. Similar to the guanidinium group of arginine, the cis amidine moiety generated a HB to the glutamic acid located at the bottom of the binding site. The inhibitor also $\pi$ stacked with the heme group. The 4-cyanobenzoylpiperidinyl tail of the inhibitor was located above the heme moiety where it packed with Gln257, Arg260, Pro344, Ala345 and Arg382. The rigid tail of the inhibitor forced a rotation of the Gln257 residue of iNOS. This is referred to by the authors as the Gln open conformation of iNOS. The rotation of Gln257 generates a conformational change at Arg260. This shift is stabilized by a HB interaction between Arg260 and Thr277. The opening of this pocket upon inhibitor binding is not observed for eNOS and nNOS as Thr277 of iNOS is replaced by the sterically bulkier Asn269/498. The authors suggested that this pocket opening forms the basis for the iNOS selectivity observed with these compounds. An image of the Gln open conformation of murine iNOS with compound $\mathbf{1 3}$ bound is provided in Fig. (19).

An alternative approach was adopted by Ji et al., [72] who described fragment hopping as a de novo inhibitor design approach that focused on the derivation of the "minimal pharmacophore element" for each NOS isoform. Sites for both ligand binding and NOS enzyme selectivity can be considered for deriving this minimal pharmacophore element. Building on a previous study [66] the active site of NOS was again divided into the four pockets $\mathrm{S}, \mathrm{M}, \mathrm{C} 1$ and $\mathrm{C} 2$. The $\mathrm{S}$ pocket is found above the heme ring while the $M$ pocket is located between the substrate catalytic site and the substrate access channel. Again, the $\mathrm{C} 1$ and $\mathrm{C} 2$ pockets are slightly removed from the substrate binding cavity and constitute the substrate access channel (Fig. 16).

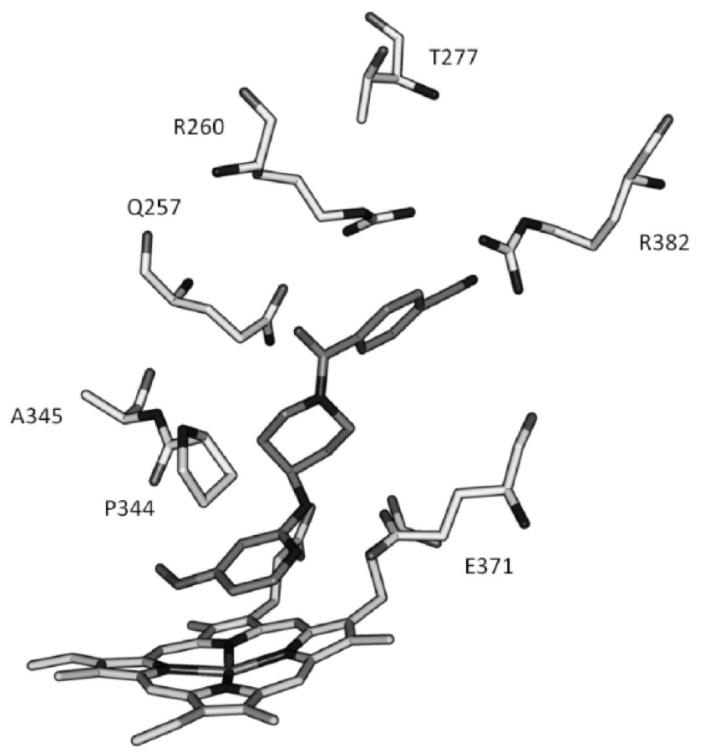

Fig. (19). Gln open conformation of iNOS with compound 13 bound. (PDB:3EAI) [68].

For selective nNOS inhibitor design an aminidino group was positioned close to Glu592; a nitrogen atom was near to the selective region defined by Asp597 of rat nNOS; three nitrogen atoms were placed close to the heme propionate to form a charge-charge interaction and HBs; in the S pocket, hydrophobic and/or steric interactions played important roles in ligand binding [72].

Based on each minimal pharmacophoric element, fragments with different chemotypes were generated using a fragment and a bioisostere library. Fragments were docked into the active site of nNOS, where the corresponding pharmacophore features were located, and subsequently linked. To circumvent issues arising from synthetic feasibility, common chemical bonds in drugs or drug candidates were considered preferentially [72]. A 2-amino pyridine compound, compound 14, which exhibited nano-molar rat nNOS inhibitory potency and 1,000-fold rat nNOS selectivity over bovine eNOS, was identified (Fig. 20).

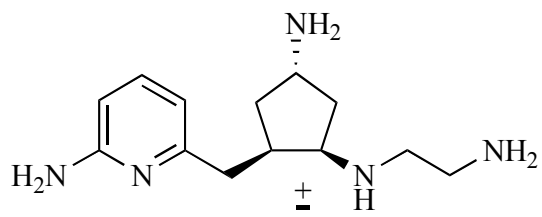

Fig. (20). Compound 14 developed by fragment screening [72]. 
The 2-aminopyridine 14, (Fig. 20), is quite polar and may not cross the blood brain barrier (BBB). As a result, Ji et al. built on this work by designing nNOS inhibitors with increased lipophilicity and optimized in vivo potency and selectivity [73]. In the GRID [68] analysis of rat nNOS, two hydrophobic areas were identified, one surrounded by Met336, Leu337, Tyr706 and Trp306 in the C1 pocket and another lined by Pro565, Ala566, Val567 and Phe584 in the $\mathrm{S}$ pocket (Fig. 16). In addition, two significant areas for steric probes were identified, one in the $\mathrm{S}$ and one in the $\mathrm{M}$ pocket. These regions were used to generate minimal pharmacophoric elements. Several compounds were generated with the LUDI program [74] which employed lipophilic fragments for lead optimization. This fragment-based method allowed the development of compounds with improved pharmaceutical properties and enhanced potency and selectivity. One such compound is the 2-aminopyridine $\mathbf{1 5}$, which has a $\mathrm{K}_{\mathrm{i}}$ of $0.014 \mu \mathrm{M}$ molar for rat nNOS inhibition and 2,000 fold selectivity over bovine eNOS and 290 fold over murine iNOS. The 2-aminopyridine 15 was initially tested as mixture of diastereomers [73] (Fig. 21). The four stereoisomers were subsequently resolved [75] (Fig. 21).

The binding modes of the enantiomers $15 S, S$ and $15 R, R$ with rat nNOS were reported in detail [75]. Compound $\mathbf{1 5}$ $\boldsymbol{S}, \boldsymbol{S}$ interacts via HBs between the conserved Glu592 at the bottom of the arginine pocket and the 2-aminopyridine on the inhibitor. Water mediated HBs formed with Asp597 and the 2-aminopyridine formed a $\pi-\pi$ interaction with the heme. The flourophenyl arm was located in the hydrophobic pocket formed by Met336 and Leu337 (Fig. 15). This is referred to as the "normal" binding mode of nNOS inhibitors by the authors, with the 2-aminopyiridine interacting with Glu592. Interestingly the $R$ configured inhibitor $(\mathbf{1 5} \boldsymbol{R}, \boldsymbol{R})$, adopted a different and novel binding mode with rat nNOS. This "flipped" binding mode saw the flourophenyl group orientated above the heme moiety. This then formed a $\pi$ stacking interaction with the porphyrin ring. The 2-aminopyridine motif extended away from the heme moiety and induced a conformational shift in Tyr706, causing this residue to move away from the aminopyridine. The aminopyridine then formed a bifurcated salt bridge with the heme propionate A, as well as a $\pi$ stacking interaction with the Tyr706. HB interactions are also observed between the pyrrolidine ring and the heme propionate $\mathrm{B}$.
The $R, R$ stereoisomer possesses remarkable selectivity, with the rat nNOS $\mathrm{K}_{\mathrm{i}}$ value being 3,800 and 700 times lower than that for bovine eNOS and murine iNOS respectively. In rat nNOS, the 4 methyl group is accommodated by a hydrophobic pocket comprised of Met336, Leu337 and Trp306. This pocket is not available in iNOS, hence the selectivity over this isoform. The eNOS selectivity is more difficult to explain as the crystal structure studies suggest that the binding mode for $\mathbf{1 5} \boldsymbol{R}, \boldsymbol{R}$ in eNOS and nNOS is the same [75]. Some selectivity differences between the two isoforms can be explained by residue differences between the eNOS and nNOS arginine binding pockets, with Asp597 in nNOS becoming Asn in eNOS and Met336 in nNOS becoming Val in eNOS. However mutation studies indicated that these residue differences were not the only contributory factors for selectivity [75]. Mutation studies also indicated that the flexible Tyr706 contributes significantly to binding in nNOS, while contributing very little to binding in eNOS. Therefore, targeting the Tyr706 site with these new flipped binding mode compounds offers the potential of highly selective and efficacious nNOS inhibitors.

Compounds such as $15 S, S$ and $15 R, R$ have great potential as nNOS inhibitors. However, their development was hampered by their somewhat poor "drug-like" properties as both $15 S, S$ and $15 R, R$ have a large number of rotatable bonds and contain several ionisable groups. Attempts have been made to improve the drug-like features of these compounds and to make them more pharmacokinetically and pharmacodynamically favourable [76]. These studies resulted in further modifications to the 2-aminopyridines and generated compounds such as $\mathbf{1 6}$ and 17, shown in Fig. (22).

Compound 16 has a $\mathrm{K}_{\mathrm{i}}$ of $7 \mathrm{nM}$ for rat $\mathrm{nNOS}, 2,667$ fold selectivity over bovine eNOS and 806 fold selectivity over murine iNOS [76]. Compound $\mathbf{1 6}$ was shown to adopt the flipped mode of binding (Fig. 23), as previously described, where the 2-aminopyridine interacts with Tyr706 to improve the binding affinity for nNOS [77]. As before, inverting both stereocenters (compound 17) resulted in a switching of binding mode to the "normal" mode (Fig. 24), indicating the crucial role stereochemical considerations must play in nNOS inhibitor design (Figs. 23 and 24). Compound $\mathbf{1 7}$ has a Ki of $220 \mathrm{nM}$ for rat nNOS, 270 fold selectivity over bovine eNOS and 60 fold selectivity over murine iNOS [78].<smiles>Cc1cc(N)nc(C[C@@H]2CNC[C@H]2NCCNCCc2cccc(F)c2)c1</smiles><smiles>[R16][C@H]1CNC[C@@H]1NCCNCCc1cccc(F)c1</smiles><smiles>[R10]N[C@H]1CNC[C@@H]1Cc1cc(C)cc(N)n1</smiles><smiles>[R]SN[C@H]1CNC[C@@H]1Cc1cc(C)cc(N)n1</smiles>

Fig. (21). Unresolved aminopyridine 15 [73] and the subsequently resolved stereoisomers [75]. The $3 S, 4 S$ (compound $15 S, S$ ) and $3 R, 4 R$ (compound $15 R, R$ ) stereoisomers had $\mathrm{K}_{\mathrm{i}}$ values of $52.2 \mathrm{nM}$ and $5.3 \mathrm{nM}$ respectively for rat $\mathrm{nNOS}$. 
Other modifications have been made to these scaffolds, such as introducing a cyclopropyl ring or a methyl group adjacent to the fluoro substituted aromatic ring (compounds 18 and 19) [79]. Difluoroination at this position has also been examined, compound 20. This has $\mathrm{IC}_{50}$ values of 0.170 $\mu \mathrm{M}, 0.046 \mu \mathrm{M}$ and $0.080 \mu \mathrm{M}$ for rat nNOS respectively $[77,79]$. All compounds were tested as racemates (Fig. 25).<smiles>Cc1cc(N)nc(C[C@@H]2CNC[C@H]2OCCNCCc2cccc(F)c2)c1</smiles><smiles>Cc1cc(N)nc(C[C@@H]2CNC[C@H]2OCCNCCc2cccc(F)c2)c1</smiles>

Fig. (22). Modified 2-aminopyridine, compound 16 and its diastereomer, compound 17 [76].

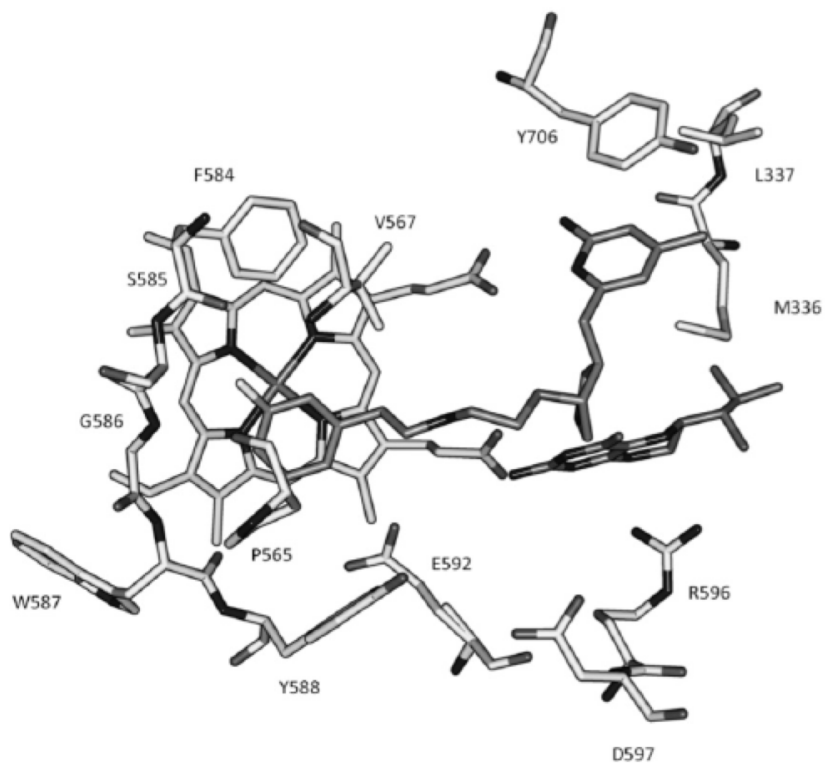

Fig. (23). Compound 16, in the flipped binding mode (PDB:3NLM) [77]. Note how Y706 is orientated to interact with the 2 aminopyridine ring.

Huang et al. [76] also developed a series of pyrrolidinebased 2-aminopyridines that exhibited a "normal" and "flipped" binding mode in rat nNOS. Both the binding mode, and the mechanism by which the ligand leaves the binding pocket of nNOS, was explored using steered molecular dynamics (SMD). In the SMD approach, forces are applied to a ligand to manipulate its structure by pulling it along desired degrees of freedom. Regions A, B and $\mathrm{C}$ were defined in the binding site (Fig. 26) and the type of moiety that could bind in each region was postulated. Region A could bind an aromatic ring facilitating stacking with the heme and interactions with Glu592. Region B could be the anchoring component that would interact with heme propionate A or Asp597.
Finally, region $\mathrm{C}$ could be an aminopyridine fragment to enhance affinity through the bifurcated $\mathrm{HBs}$ with heme propionate D and the $\pi$-stacking interaction with Tyr706.

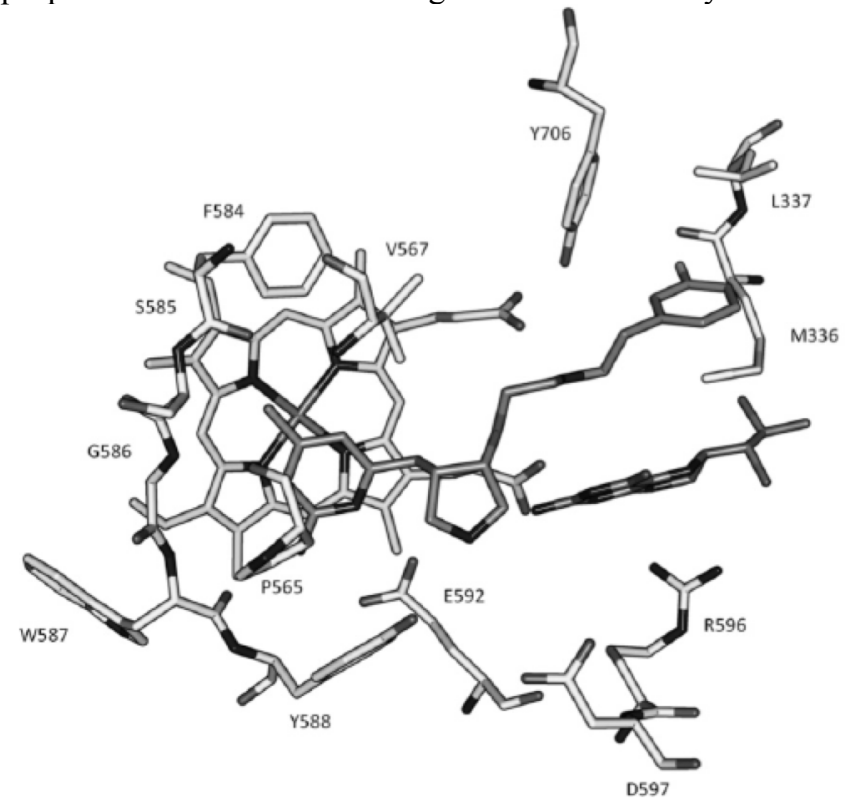

Fig. (24). Compound 17, in the normal binding mode. (PDB:3NLK). Note how the Y706 does not position itself to interact with the flourophenyl ring [77].<smiles>Cc1cc(N)nc(C[C@H]2CNC[C@@H]2OC(C)(C)C)c1</smiles><smiles>Cc1cc(N)nc(C[C@@H]2CNC[C@H]2OCCNC(C)Cc2cccc(F)c2)c1</smiles><smiles>Cc1cc(N)nc(C[C@@H]2CNC[C@H]2OCCNCC(F)(F)c2cccc(F)c2)c1</smiles>

Compound 20

Fig (25). Cyclopropyl (compound 18) [79], methyl (compound 19) [79] and difluoro (compound 20) [77] substituted scaffolds.

A series of compounds containing two pyridine rings were synthesised to validate the simulation predictions [76]. Compound 21 (Fig. 27) exhibited a $K_{i}$ of $0.03 \mu \mathrm{M}$ for rat nNOS with a rat nNOS over bovine eNOS selectivity of 1,117 and a rat nNOS over murine iNOS selectivity of 619 . Compound 21 also demonstrated improved membrane permeability, at $3 \mu \mathrm{M}$, for the aminopyridine based nNOS inhibitors. The metabolic stability of $\mathbf{2 1}$ was also examined. The in vitro metabolic rate was $0.02(\mathrm{nmol} / \mathrm{min} / \mathrm{mg}$ protein) with $85 \%$ of compound 21 remaining after $60 \mathrm{~min}$ in the presence of NADPH [76].

Despite the success of $\mathbf{2 1}$ and other similar compounds, the chiral pyrrolidine containing aminopyridine scaffold is 
not particularly suitable for further development due to synthesis and purification difficulties. In addition, the scaffold was not very drug like, having multiple ionisable groups and poor BBB characteristics. As previously discussed, reports on the 2-aminopyridine motif indicated that it was capable of binding to NOS in two orientations, the "normal" and "flipped" depending on the stereochemistry of the pyrrolidine ring substituents. Xue et al. reasoned that by combining two identical 2-aminopyridine motifs via a central linker both binding modes could be achieved with a single compound [80]. The most potent compound to result from this structure activity relationship (SAR) study was compound 22 (Fig. 28) which had a $K_{i}$ of $25 \mathrm{nM}$ for rat nNOS, and a 107 and 58 fold selectivity over bovine eNOS and murine iNOS respectively [80].

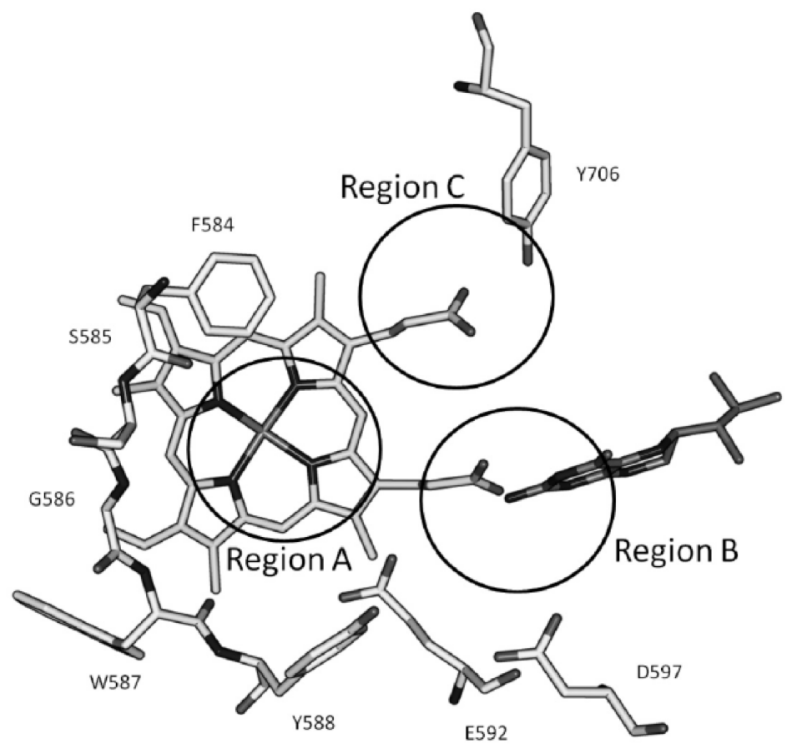

Fig. (26). Huang's regions $\mathrm{A}, \mathrm{B}$ and $\mathrm{C}$ of the rat nNOS arginine binding pocket [76] (PDB: 1K2R, unpublished).<smiles>Cc1cc(N)nc(C[C@@H]2CNC[C@H]2OCCCCCc2cccc(N)n2)c1</smiles>

Fig. (27). Huang et al.’s aminopyridine, compound 21 [76].<smiles>Cc1cc(N)nc(CCc2cncc(CCc3cc(C)cc(N)n3)c2)c1</smiles>

Fig. (28). Xue et al.'s compound 22 [80].

One of the most interesting features of compound $\mathbf{2 2}$ was its binding mode as determined by crystallization of compound 22 with rat nNOS (Fig 29). [81] It was observed, as expected, that compound $\mathbf{2 2}$ used one of the 2-aminopyridine moieties to form a network of HBs with Glu592 and Trp587. The second 2-aminopyridine moiety formed HB interactions with one of the heme propionates as well as a $\pi-\pi$ interaction with Tyr706. Unexpectedly, a second molecule of compound 22 binds to the $\mathrm{BH}_{4}$ binding site by using the central pyridine nitrogen to interact with the zinc atom present in the $\mathrm{BH}_{4}$ site. This results in the displacement of the $\mathrm{BH}_{4}$ and a rearrangement of several residues, in particular Arg596, which moves to interact with Glu592 and Asp600 of the substrate binding site. This movement opens a second zinc binding site in nNOS. The binding of a second zinc atom results in a tightening of the dimer interface in nNOS. This opening of a second zinc binding site is not observed in eNOS, potentially due to the tighter dimer interface of this enzyme. This may explain the selectivity of compound $\mathbf{2 2}$ for nNOS over eNOS.

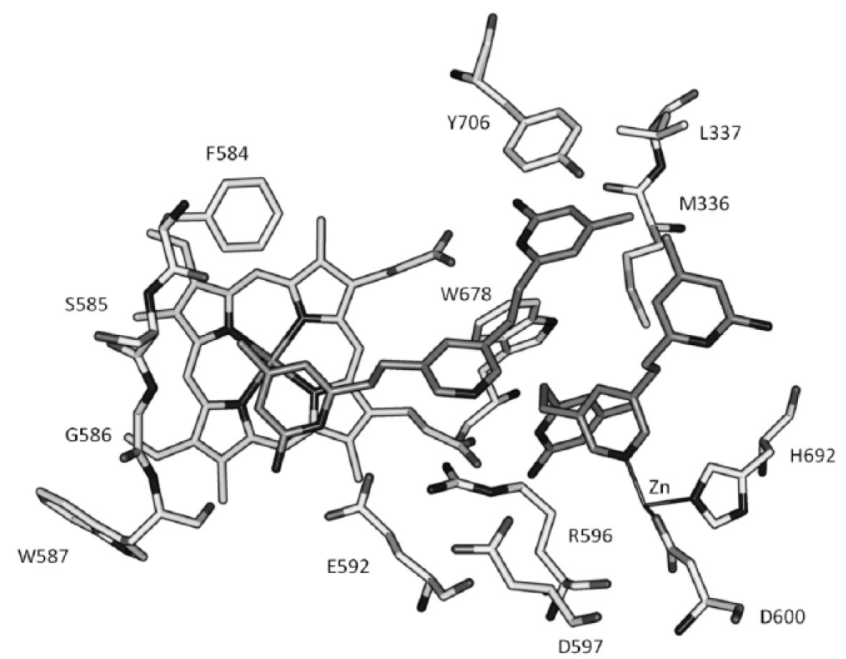

Fig. (29). Dual diaminopyridine compound 22 binding to both the arginine and the $\mathrm{BH}_{4}$ binding sites. (PDB: 3N5W) [81].

Several pharmaceutical companies have also explored the use of 2-aminopyridines as nNOS inhibitors. In a 2004 study, Pfizer published a series of eight compounds which inhibited human nNOS, the most efficacious of which was compound 23, with a $\mathrm{IC}_{50}$ of $54 \mathrm{nM}$ [82] (Fig. 30). Studies exploring the binding mode of this family of compounds were not published. Animal studies employing the Pfizer compounds were mentioned in their 2004 paper but did not appear in the literature to the best of our knowledge.

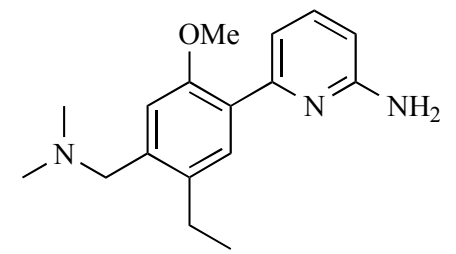

Fig. (30). Pfizer's 2-aminopyridine, compound 23 [82].

\subsubsection{MD Studies of Binding Modes of L-NNA and 2- Aminopyridines}

Compound 13, Fig. (18) and compound $15 \boldsymbol{R}, \boldsymbol{R}$, Fig. (21) were previously synthesised and evaluated by Garcin 
et al. [71] and Ji et al. [75] respectively. Recently, Oliveira et al. studied the precise binding mode of L-NNA and the protonated forms of $\mathbf{1 3}$ and $\mathbf{1 5} \boldsymbol{R}, \boldsymbol{R}$ (Fig. (31) using computational methods. Oliveira et al. first validated their compound docking protocol by re-docking the crystal structure ligand into the binding pocket. Following docking of the protonated versions of compound $\mathbf{1 3}$ and $\mathbf{1 5} \boldsymbol{R}, \boldsymbol{R}$ they implemented $8 \mathrm{~ns}$ MD simulations for murine iNOS, bovine eNOS and rat nNOS monomers [83]. MD simulations are frequently used to monitor interactions and conformational changes over a time period in an effort to incorporate receptor/ligand flexibility and induced fit into studies. This publication offered an excellent insight into the predicted binding modes of the two main nNOS inhibitor classes, substituted arginines and 2-aminopyrines, and so will be discussed in detail.

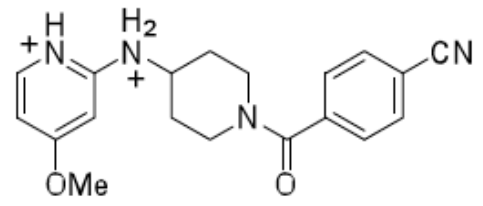

Protonated compound 13

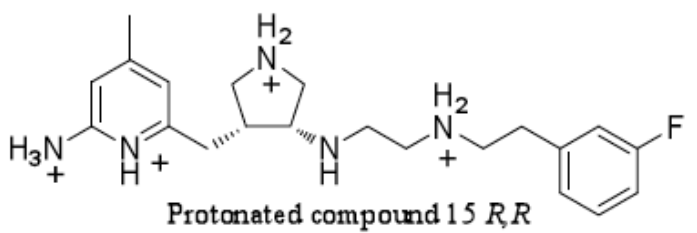

Fig. (31). Protonated versions of compound 13 [71] and compound $15 R, R$ [75] computationally studied by Oliveira et al. [83]. The medicinal chemistry papers of Garcin et al. [71] and Ji et al. [75] reported the original synthesis and evaluation of 13 and $15 R, R$ from which the protonated species shown here are derived.

L-NNA is moderately selective for nNOS over eNOS and iNOS with $\mathrm{IC}_{50}$ values of $0.29 \mu \mathrm{M}, 0.35 \mu \mathrm{M}$ and $3.1 \mu \mathrm{M}$ respectively. The MD simulations revealed that this selectivity was due to two binding modes which L-NNA could adopt. In nNOS, the inhibitors bind in an "extended" conformation (Fig. 13). This is facilitated by an interaction which forms between the L-NNA carbonyl group and Arg481. This interaction cannot be achieved in iNOS due to a change of Asn498 in nNOS to Thr277 in iNOS. In nNOS, Asn498 induces a rotation in $\operatorname{Arg} 481$, allowing $\operatorname{Arg} 481$ to interact with the carbonyl group of L-NNA. In iNOS, Thr277 does not induce rotation in the corresponding arginine (Arg260). L-NNA therefore adopts a "curled" conformation in iNOS, pushing the carbonyl group close to Asp376. This results in electronic repulsion between the inhibitor and the binding site. This explains the higher binding affinity of LNNA for nNOS over iNOS.

L-NNA uses this "curled" mode of binding in eNOS for similar reasons. The inhibitor is slightly more potent against eNOS than iNOS due to the change of Asp376 in iNOS to Asn368 in eNOS. This mutation reduces the electronic repulsion between the binding site and L-NNA in eNOS, which results in tighter binding. The affinity of the protonated aminopyridine $\mathbf{1 3}$ for iNOS could be explained by the formation of an iNOS specific sub-pocket upon binding. The ability of Glu363 to adopt different conformations has already been observed in X-ray crystal structures. The lack of affinity for eNOS was associated with a conformational change in Glu363 [84,85].

In all three isoforms the protonated version of $\mathbf{1 3}$ adopts the "normal" binding mode, with the 2-aminopyridine moiety positioned near the heam moiety, allowing it to form a bidentate HB with a Glu residue (Glu592 in rat nNOS, Glu363 in bovine eNOS and Glu371 murine iNOS). The binding of the 2-aminopyridine moves the pyridine ring parallel with the heme in iNOS and nNOS, thus facilitating formation of $\pi-\pi$ interactions between the two aromatic rings. The bulkier residues of the eNOS binding pocket do not allow the aminopyridine and the heme rings to orientate themselves parallel to each other. Therefore the $\pi-\pi$ interaction does not form in eNOS. Oliveria et al. suggest that this explains the lower affinity of protonated compound $\mathbf{1 3}$ for eNOS over iNOS and nNOS. In iNOS and nNOS the $\pi-\pi$ interaction pushes the cyanobenzyl above the heme moiety allowing it to interact with $G \ln 257$ in iNOS and $G \ln 478$ of nNOS. In iNOS, this induces the Gln "open" conformation as previously described by Garcin [71]. The Gln "open" conformation is not observed for nNOS, thus explaining why the protonated version of compound $\mathbf{1 3}$ favours iNOS over nNOS.

The MD simulations suggested why the protonated form of compound $\mathbf{1 5} \boldsymbol{R}, \boldsymbol{R}$ favours nNOS binding over eNOS or iNOS. Binding of the protonated compound $15 \boldsymbol{R}, \boldsymbol{R}$ to eNOS results in rotation of Glu363 with an associated energy penalty of $1-2 \mathrm{kcal} \mathrm{mol}^{-1}$ [83]. Also, the nNOS arginine binding pocket was calculated to have a volume of $2203+/-8.3 \AA^{3}$, while eNOS is slightly larger at $2489.0+/-7.7 \AA^{3}$ [83]. The larger pocket of eNOS is suggested to result in weaker Van der Waals interactions between the protonated form of $\mathbf{1 5}$ and eNOS. In iNOS, it was observed that the fluorophenyl group is not parallel to the heme moiety while in nNOS and eNOS the two rings are parallel, thus enabling $\pi-\pi$ interactions. This may explain why the protonated compound $\mathbf{1 5}$ $\boldsymbol{R}, \boldsymbol{R}$ is not as potent against iNOS as it is for eNOS and nNOS.

\subsubsection{Thiophene Scaffold Inhibitors}

AstraZeneca have published several thiophene containing compounds that act as NOS inhibitors. These compounds retained the same "normal" binding interactions within the rat nNOS arginine pocket where the amidine interacts with the conserved Glu592 and the secondary amine forms an interaction with the heme propionate [86]. The chlorophenyl ring is accommodated by the hydrophobic pocket consisting of Tyr706, Leu337 and Met336 and the interaction is further stabilised by pi stacking with the Tyr706 aromatic ring. Compound $\mathbf{2 4}$ has $\mathrm{IC}_{50}$ values of $0.035 \mu \mathrm{M}, 3.5 \mu \mathrm{M}$ and $5 \mu \mathrm{M}$ against nNOS, eNOS and iNOS respectively (Fig. 32).

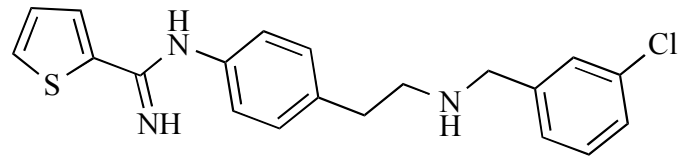

Fig. (32). AstraZeneca's thiophene based inhibitor, compound 24 [86]. 
Sanofi-Aventis have also examined thiophene scaffolds as potentially selective nNOS inhibitors. In a 2011 publication Liang et al. reported a series of compounds with $\mathrm{IC}_{50}$ values ranging from $17 \mathrm{nM}$ to $706 \mathrm{nM}$ against $\mathrm{nNOS}$ [87]. The most potent of these was compound 25 (Fig. 33). This displayed a 1,664 fold selectivity for rat nNOS over bovine eNOS.

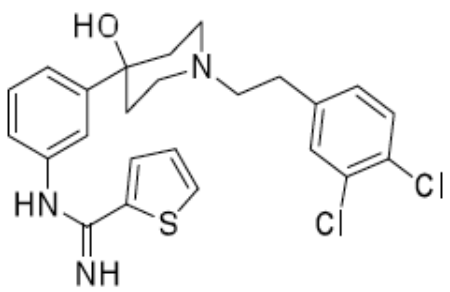

Fig. (33). Compound 25, with $\mathrm{IC}_{50}$ of $17 \mathrm{nM}$ for rat $\mathrm{nNOS}$ [87].

Neuraxon employed a thiophene/guanidinium combination in their SAR studies [88]. Here they developed a series of compounds containing a thiophene, a guanidinium group and a hydrocarbon chain linked to an amine functionality. Their most successful inhibitor was compound 26 (Fig. 34) with an $\mathrm{IC}_{50}$ of $97 \mathrm{nM}$ for human nNOS [88]. This compound displayed 33 fold and greater than 100 fold, selectivity over human eNOS and human iNOS respectively.

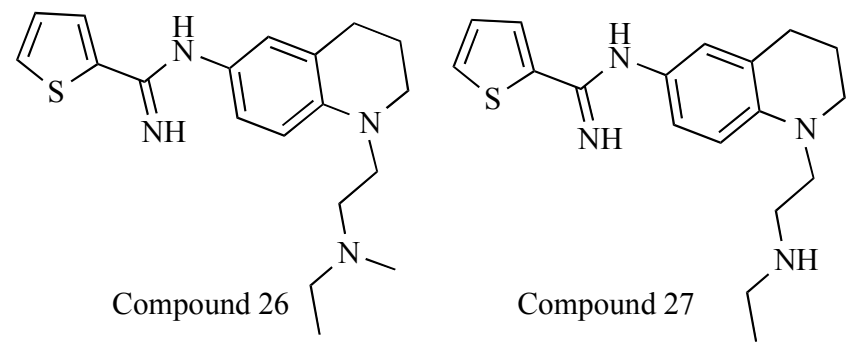

Fig. (34). Neuraxon's nNOS inhibitor compound 26 and the secondary amine version developed to ameliorate hERG channel interactions, compound 27 [88].

Replacement of the methyl group on the tertiary nitrogen with a hydrogen (compound 27, Fig. 34) was observed to greatly reduce $\mathrm{hERG}$ channel interaction, with the $\mathrm{IC}_{50}$ increasing to $139 \mathrm{nM}$. This secondary amine containing compound was observed to be orally bioavailable and effective in the Chung pain model of rats [89]. The binding mode of this compound has not been elucidated to the best of our knowledge.

\subsubsection{FeS Coordinating Inhibitors}

Imidazole containing compounds have also been observed to bind to the arginine binding site, but in a slightly different manner. This class of compound coordinate to the heme $\mathrm{Fe}$ at the centre of the active site via an imidazole nitrogen. Imidazole itself is a weak inhibitor of nNOS, with an $\mathrm{IC}_{50}$ of $290.6 \mu \mathrm{M}$ [90]. Various substituents have been added to imidazole in an attempt to improve its efficacy as a nNOS inhibitor. These substituents include phenyl rings (compound 28) [91] and various amino acids (compound 29) [92, 93] (Fig. 35).<smiles>c1ccc(-n2ccnc2)cc1</smiles>

Compound 28<smiles>N[C@@H](CCCn1ccnc1)C(=O)O</smiles>

Compound 29
Fig. (35). Phenyl [91] and amino acid [93] substituted imidazoles, compounds 28 and 29, with nNOS IC $_{50}$ values of $25 \mu \mathrm{M}$ and $19 \mu \mathrm{M}$ respectively.

Other heme co-ordinating inhibitors have been designed using in silico methods. L-thiocitrulline, an arginine analogue with the terminal guanidine-nitrogen replaced by sulphur, was active against rat nNOS and reported to coordinate to the heme iron [94]. Litzinger et al. [95] proposed combining the key features of L-thiocitrulline with amino acid substituted imidazoles. This new class of inhibitor was docked with rat nNOS using the FlexX [96] program and compound 30 (Fig. 36) was predicted to be positioned with the sulphur close to the heme and coordinated to the $\mathrm{Fe}$.

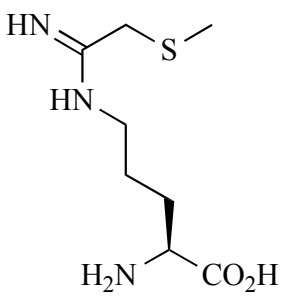

Compound 30

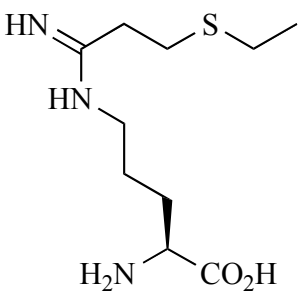

Compound 31
Fig. (36). Iron co-ordination nNOS inhibitors, compounds $\mathbf{3 0}$ and $31[95,97]$.

Compound 30 exhibited good potency $\left(\mathrm{K}_{\mathrm{i}}\right.$ of $\left.0.37 \mathrm{uM}\right)$ and moderate selectivity for rat nNOS (185 fold for rat nNOS over bovine eNOS and 3.12 fold for rat nNOS over murine iNOS). In contrast to the docking predictions, experimental difference absorption spectra indicated a type I spectrum when compound $\mathbf{3 0}$ was added to imidazole saturated nNOS. Absorption spectra categorised as a type I spectra, with a peak at $\sim 400 \mathrm{~nm}$ and a trough at $437 \mathrm{~nm}$, are indicative of a pentacoordinate high spin heme iron. While a type II spectrum, such as that for a known Fe coordinating ligand (e.g. imidazole), displays a peak at $432 \mathrm{~nm}$ and a trough at $393 \mathrm{~nm}$. The observed type I spectrum indicates that the sulphur containing chain does not interact with the heme iron as predicted. Subsequently, the group postulated that the sulphur containing chain binds preferentially in the hydrophobic pocket at the top of the active site [95].

The same group then analyzed potential ligand-enzyme interactions in the hydrophobic pocket defined by Pro565, Val567, and Phe584 of rat nNOS [97]. This pocket can also accommodate small alkyl groups, with inhibitors anchored in the active site through a HB with Glu592. Based on this analysis compound 31 (Fig. 36) was designed, which was confirmed to be a type II ligand by UV-vis spectrophotometry and crystallography (type II inhibitors convert the highspin heme of $\mathrm{BH}_{4}-\mathrm{nNOS}$ to a low spin state, resulting in a red shift in the Soret absorption and a type II visible difference spectrum) [97]. The crystal structure of compound $\mathbf{3 1}$ 
with rat nNOS revealed that the two methylene groups, separating the amidine from the sulphur, afforded the flexibility needed to place the sulphur directly over the heme iron. The terminal ethyl group fits into the hydrophobic pocket formed by Pro565, Val567 and Phe584 and the Fe-S distance is 2.5$2.6 \AA$ (Fig. 37).

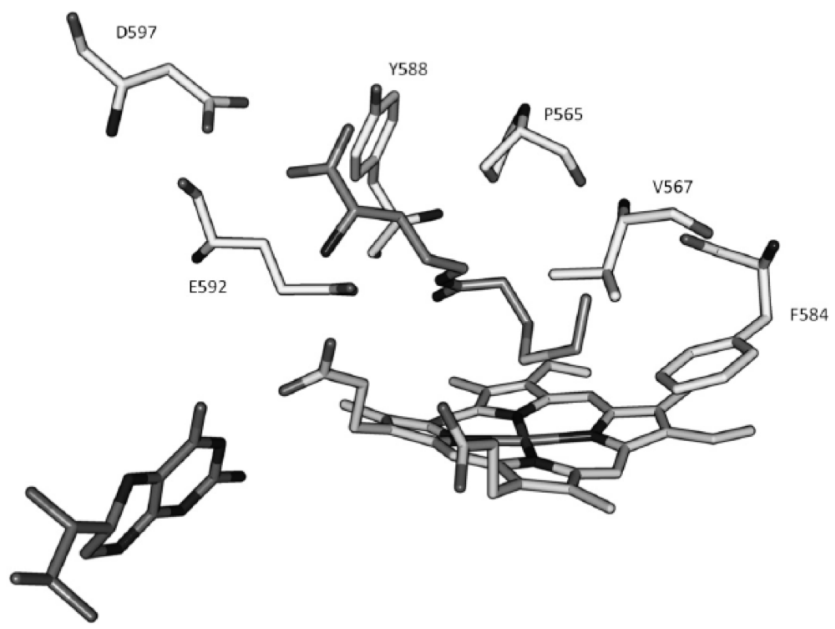

Fig. (37). Compound 31 co-crystallized with rat nNOS (PDB:3JT4) [97].

\subsubsection{Recent Advances in nNOS Inhibitor Design \& Opti- mization}

Virtual screening is often used as an alternative to high throughput screening, in an effort to reduce both cost and time [98]. The approach can be validated initially through the use of theoretical test/validation sets and subsequently through experimental evaluation of the identified compounds. Xu et al. [99] performed a tiered virtual screening study incorporating development of a seven feature NOS pharmacophore, a Comparative Molecular Field Analysis (CoMFA) comparison and docking studies using a rat nNOS crystal structure. The pharmacophore model incorporated three hydrophobes, one donor atom, one acceptor atom and two positive nitrogens and was in general agreement with the CoMFA model. Here, tiered virtual screening of the Specs database of 197,000 compounds was pursued by filtering first by the pharmacophore query, by Lipiniski rules and by Qfit [100]. Subsequently, the filtered compounds were further examined by flexible docking. From this 10 compounds were identified as potential selective human nNOS inhibitors but remain to be experimentally validated. The top three ranking compounds from this screen are shown in Table $\mathbf{2}$.

Recently, Kumar et al. [101] developed a QSAR model of a series of 3,4-dihydro-1-isoquinolinamines and thienopyridines that were reported as potent, highly selective inhibitors of nNOS and eNOS. The QSAR models for nNOS and eNOS inhibition potency were indicated to involve a hydrophobic $(\mathrm{Clog} \mathrm{P})$ and a steric (calculated molar refractivity, CMR) interaction respectively. Through docking studies the possible orientations of the compounds with the enzymes were modelled. Compound 32 (Fig. 38) was predicted to form a $\mathrm{HB}$ through the 6- $\mathrm{NH}_{2}$ group with Pro450 and $3 \mathrm{HBs}$ between the 10- $\mathrm{NH}_{2}$ group and Val449, Pro450 and Pro451 of eNOS. Alternatively, compound $\mathbf{3 3}$ was predicted to form
HBs through its 6- $\mathrm{NH}_{2}$ group with Ala446, Trp447 and Val449 of nNOS.

Table 2. Xu et al.'s predicted nNOS inhibitors [99].

\begin{tabular}{|l|l|l|l|}
\hline Structure & $\begin{array}{c}\text { Dock } \\
\text { Score }\end{array}$ & QFIT \\
\hline
\end{tabular}<smiles>NC1=NC(N)Cc2ccsc21</smiles>

Fig. (38). Kumar et al.'s compounds 32 and 33 utilised in a QSAR study [101].

\section{PHARMACOKINETICS OF nNOS INHIBITORS}

The BBB blocks certain drugs, chemical compounds and viruses from gaining access to the CNS from the bloodstream. In general, CNS drugs have a smaller range of molecular weights, and smaller number of hydrogen bond donor and acceptors than general therapeutics [102]. A large number of charges and hydrogen bond donors can impede the ability of molecules to cross the BBB and thereby limit the effectiveness of potential neurological therapeutics.

In the nNOS arena, a number of medicinal chemistry approaches have been pursued to improve PK properties $[103,104]$. For example, a prodrug approach was employed that involved replacing one of the secondary amino groups on a pteridine NOS inhibitor (which binds in the $\mathrm{BH}_{4}$ pocket) with an amide or carbamate [36], (scaffolds shown in Fig. 6). This was reported to improve BBB penetration by lowering the charge, removing two HBDs and raising the predicted $\log \mathrm{D}$ [36]. Additionally, amino groups which exhibited a high pKa have been replaced by ethers and amides in 2-aminopyridines [105], (Fig. 39). The resultant ether analogue maintained a similar potency and selectivity but with an increased ability to penetrate the BBB, as evidenced by an increased brain to blood concentration ratio [105]. Acetylated and carbamoylated prodrug analogues of compound 21, 
reported by Silverman and co-workers, have increased lipophilicity and lowered charge, but surprisingly, did not cause an increase in BBB penetration (Fig. 40) [106]. Over a 20 minute experiment there was little difference between the overall brain concentrations of the tested prodrug analogues of 21.<smiles>Cc1cc(N)nc(C[C@@H]2CNC[C@H]2NCCNCCc2cccc(F)c2)c1</smiles><smiles>CC(C)(C)[C@H]1CNC[C@@H]1OCCNCCc1cccc(F)c1</smiles>

Fig. (39). Compound $15 S, S$ [72] with a secondary amine, and compound 16 [73] with an ester linkage which were used to study how substitution patterns affected passage of nNOS inhibitors across the BBB [105].<smiles>COC(=O)N(CCO[C@H]1CNC[C@@H]1Cc1cc(C)cc(N)n1)CCc1cccc(F)c1</smiles>

Fig. (40). Compound 21 and three prodrug analogues of same. Silverman et al. 2009 [106].

The addition of an intramolecular HB is another known strategy used in PK and BBB optimisation of novel inhibitors for a variety of enzymes [107-111]. In an effort to exploit this strategy, nNOS aminopyridine inhibitors were designed with intramolecular hydrogen bonding motifs in the hope of improving cell membrane permeability [112]. In this study, inhibitors such as compound $\mathbf{3 4}$ were hypothesised to form a "closed" conformation through intramolecular HB formation, which would decrease the overall polarity of the compound and potentially improve BBB permeability. Once the inhibitor bound to nNOS it might form alternative intermolecular interactions and stabilize an "open" conformation [112] (Fig 42). Some synthesised compounds capable of intramolecular HB formation exhibited an improved relative permeability index (RPI), indicative of an increased cell membrane penetration ability e.g. a RPI of 3.1 was observed for compound 34 (Fig. 41). However, it appears that incorporation of an intra-molecular HB was not sufficient to enhance cell membrane permeability for other compounds with lipophilicity playing a larger role [112].

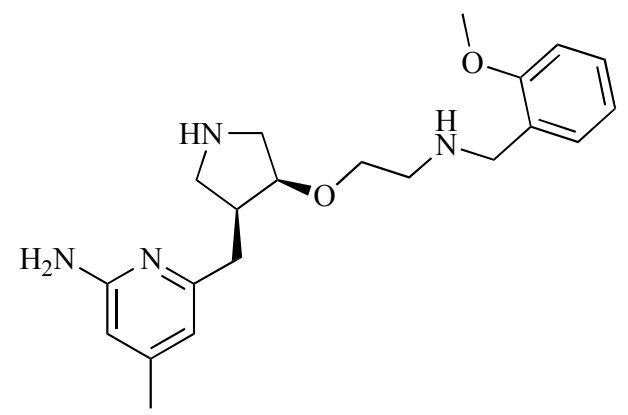

Fig. (41). Labby et al.'s aminopyridine based inhibitor, compound 34. This can form intramolecular HB between the secondary amine hydrogen and the methyl ester oxygen. This interaction is lost on inhibitor binding to nNOS [112].

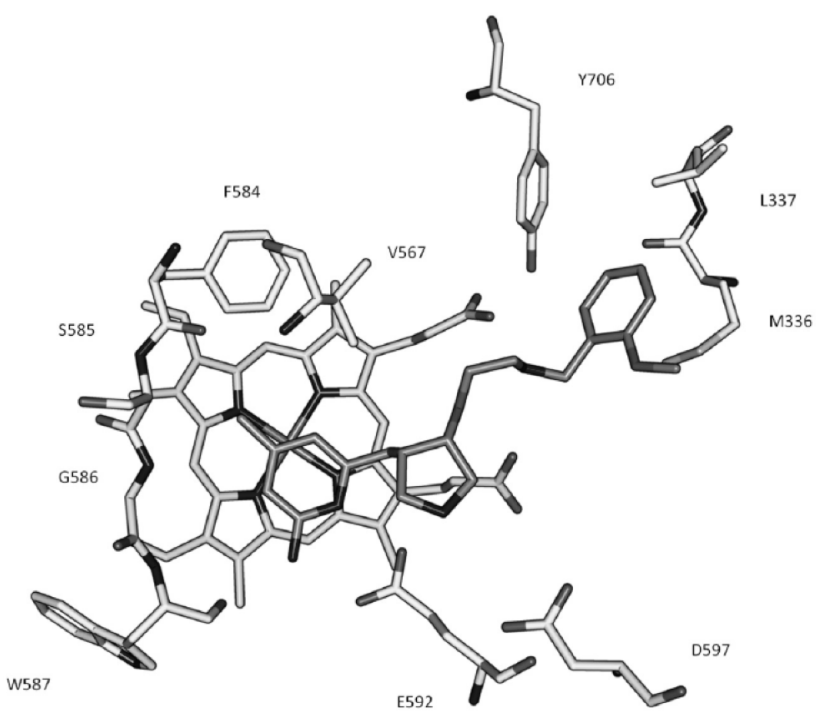

Fig. (42). Compound 34 bound to rat nNOS arginine site. The intramolecular hydrogen bond interaction between the secondary amine hydrogen and the oxygen of the methyl ester is disrupted on inhibitor binding. This was referred to as "open" binding of the inhibitor (PDB: 3TYM) [112].

Xue et al. [77] introduced an electron withdrawing $\mathrm{CF}_{2}$ moiety to aminopyridine inhibitors in an effort to reduce the basicity of their hit compound and improve its bioavailability (Fig. 43). Molecular Mechanics Poisson-Boltzmann/Surface Area (MM-PBSA) calculations, used to compute the free energy for various protonation states of the molecules, were performed and compared with the experimental free energy data. This confirmed the likelihood that the low pKa amino 
group is partially protonated when bound to the nNOS active site. The experimental pharmacokinetic data illustrated that the addition of $\mathrm{CF}_{2}$ had a marked effect on in vivo stability and oral bioavailability. For example, compound 20 exhibited an in vivo compound half-life $\left(\mathrm{t}_{1 / 2}\right)$ for i.v. dosing at 1 $\mathrm{mg} / \mathrm{kg}$ in rats of $7.5 \mathrm{hr}$; a $\mathrm{t}_{1 / 2}$ for oral dosing of $3.7 \mathrm{hr}$ and an oral bioavailability of $22.2 \%$ whereas compound 16 had a $t_{1 / 2}$ for i.v. dosing at $1 \mathrm{mg} / \mathrm{kg}$ in rats of $0.33 \mathrm{hr}$; a t $t_{1 / 2}$ for oral dosing that was too low to measure and an oral bioavailability of essentially $0 \%$, (Fig. 43).<smiles>Cc1cc(N)nc(C[C@@H]2CNC[C@H]2OCCNCCc2cccc(F)c2)c1</smiles><smiles>Cc1cc(N)nc(C[C@@H]2CNC[C@H]2OCCNCC(F)(F)c2cccc(F)c2)c1</smiles>

Fig. (43). Aminopyridine inhibitors 16 and 20, as presented by Xue et al. [77].

In recent years, Kumar et al. [113] examined a number of computational BBB filter models and concluded that there remains an urgent need to generate larger and more diverse datasets with accurate measurements of $\log B B$ values (the logarithm value of brain to plasma concentration ratio). Additionally, other factors can influence BBB penetration e.g. plasma protein binding, active efflux from the CNS etc. However, Ji et al. [72] advocated early ADME/Tox considerations in de novo nNOS compound design, as this would allow the functional groups that potentially effect metabolic stability and toxicophores to be taken into account during the generation of the focused fragment library and the linking of fragments. Such ADME/Tox considerations included oral bioavailability (rule of 5); blood brain distribution; and metabolic stability (Metasite, http://www.moldiscovery.com/software/metasite). The group of $\mathrm{Ji}$ et al. used a property based strategy to evaluate ADME/Tox effect of molecules [114]. A similar approach has been applied to other NOS enzymes. Recently, Kartasasmita et al., [115] examined Asiatic acid derivatives as iNOS inhibitors. Their docking study was coupled with a rudimentary ADME prediction using PreADMET (http://preadmet.bmdrc.org). Where experimental PK data was available, the prediction tool was in good agreement for human intestinal absorption (HIA). Such computational tools can be used to focus at an early stage, on those inhibitors which have appropriate properties for oral administration.

\section{CONCLUSION AND FUTURE PERSPECTIVES}

A focus of this review was on the recent use of computational techniques in the design and optimization of nNOS selective inhibitors and an analysis of the success of such approaches. A variety of compound classes have been de- signed and utilized as nNOS inhibitors targeting a selection of sites, including the $\mathrm{BH}_{4}, \mathrm{CaM}, \mathrm{NADPH}$ and the arginine binding sites.

Efforts have been made to inhibit the binding of the crucial co-factor $\mathrm{BH}_{4}$ so as to slow NOS activity. This between NOS isoforms. The concern remains that in the absence of $\mathrm{BH}_{4}$ there may be a build-up of potentially harmful free radical species. Work has been conducted on inhibiting NOS$\mathrm{CaM}$ interactions. Interfering with $\mathrm{CaM}$ itself could have potentially serious consequences in vivo owing to the wide range of processes which $\mathrm{CaM}$ regulates. Also, targeting protein-protein interaction sites is considered to be difficult as the surfaces are usually solvent exposed and do not favour strong binding interactions. For the NADPH binding site of NOS, a nucleotide moiety mimicking NADPH linked to a conjugated push-pull chromophore with non-linear absorption properties has been explored as both a trigger and a shutter. However, due to the vast array of enzymes which bind NADPH and the tendency of these sites to be well conserved, it is likely that any imaging agent would suffer from a lack of specificity.

The best explored classes are the L-arginine mimics, which unsurprisingly replicate the binding mode of the natural substrate, and the 2-aminopyridines, which have been observed to bind in either a flipped or non-flipped orientation depending on substitution patterns. Other classes, including imidazole and thiophene analogues, have also been examined. While efficacious and selective compounds have been identified, challenges remain surrounding the suitability of these compounds for further development due to their pharmacokinetic properties.

Further development in the area of nNOS inhibition will rely on development of an all human isoform assay system. Throughout the literature there is inconsistency in what isoform of nNOS is used for testing (rat, porcine, human etc). There is also inconsistency in the types of assay used to test inhibitory compounds. These can vary between Griess based assays, haemoglobin conversion assays, radiolabelled assays and whole cell assays. This is compounded by the use of various isoforms for selectivity testing and examination of binding modes (comparing inhibition of rat $\mathrm{nNOS}$ with bovine eNOS for example). This issue should be somewhat addressed by the very recent publication of the first human nNOS crystal structure [116]. A move to a uniform method of testing (both NOS isoform and assay system) will allow robust comparison of results and development of more efficacious and selective nNOS inhibitors.

As evidenced in this review a substantial body of work has been conducted on nNOS inhibition using a variety of approaches. Continued work in this area has the potential to yield a clinically viable nNOS inhibitor in the near future, which could significantly improve the quality of life for those suffering from debilitating illness.

\section{ABBREVIATIONS}

$\begin{array}{ll}\mathrm{BBB} & =\text { Blood brain barrier } \\ \mathrm{CMR} & =\text { Calculated molar refractivity } \\ \mathrm{CaM} & =\text { Calmodulin }\end{array}$




$$
\begin{aligned}
& \mathrm{CBR}=\text { Calmodulin binding region } \\
& \text { CNS = Central nervous system } \\
& \text { CoMFA }=\text { Comparative molecular field analysis } \\
& \text { CoMSIA = Comparative molecular similarity index analysis } \\
& \mathrm{CPCA}=\text { Consensus principal component analysis } \\
& \text { cGMP = Cyclic guanosine 3',5'-monophosphate } \\
& \text { eNOS = Endothelial nitric oxide synthase } \\
& \text { FAD }=\text { Flavin adenine dinucleotide } \\
& \text { FMN = Flavin mononucleotide } \\
& \mathrm{HB}=\text { Hydrogen bond } \\
& \text { HBA = Hydrogen bond acceptor } \\
& \text { HBD = Hydrogen bond donor } \\
& \text { iNOS = Inducible nitric oxide synthase } \\
& \text { LBDD }=\text { Ligand based drug design } \\
& \text { MD = Molecular dynamics } \\
& \mathrm{NADPH}=\text { Nicotinamide adenine dinucleotide phosphate } \\
& \text { nNOS }=\text { Neuronal nitric oxide synthase } \\
& \text { L-NNA }=\mathrm{N}^{\omega} \text {-nitro-L-arginine } \\
& \text { L-NOHA }=N \text {-hydroxy-L-arginine } \\
& \text { NO }=\text { Nitric oxide } \\
& \text { NOS }=\text { Nitric oxide synthase } \\
& \text { NMR = Nuclear magnetic resonance } \\
& \text { PK }=\text { Pharmacokinetics } \\
& \text { Por } \quad=\text { Porphyrin } \\
& \text { QSAR = Quantitative structure activity relationship } \\
& \text { RNS = Reactive nitrogen species } \\
& \text { ROS }=\text { Reactive oxygen species } \\
& \text { RPI = Relative permeability index } \\
& \text { SMD }=\text { Steered molecular dynamics } \\
& \text { SBDD }=\text { Structure based drug design } \\
& \mathrm{BH}_{4}=\text { Tetrahydrobiopterin }
\end{aligned}
$$

\section{CONFLICT OF INTEREST}

The authors confirm that this article content has no conflict of interest.

\section{ACKNOWLEDGEMENTS}

$\mathrm{AMC}$ is supported by the BioAT PhD programme as part of the Irish Higher Education Authority (HEA) Programme for Research in Third Level Institutions (PRTLI) Cycle 5. The PRTLI is co-funded through the European Regional Development Fund (ERDF), part of the European Union Structural Funds Programme 2007-2013.

\section{REFERENCES}

[1] Miki, N.; Kawabe, Y.; Kuriyama, K. Activation of cerebral guanylate cyclase by nitric oxide. Biochem. Biophys. Res. Commun., 1977, 75(4), 851-856.
[2] Moncada, S.; Palmer, R.M.J.; Higgs, E.A. Nitric oxide: physiology, pathophysiology, and pharmacology. Pharmacol. Rev., 1991, 43(2), 109-142.

[3] Kerwin, J.F.; Lancaster, J.R.; Feldman, P.L. Nitric oxide: a new paradigm for second messengers. J. Med. Chem., 1995, 38(22), 4343-4362.

[4] Schlossmann, J.; Hofmann, F. cGMP-dependent protein kinases in drug discovery. Drug Discov. Today, 2005, 10(9), 627-634.

[5] Xu, W.; Liu, L.; Charles, I. Microencapsulated iNOS-expressing cells cause tumor suppression in mice. FASEB J., 2002, 1987(2), 213-230.

[6] Andrew, P.J.; Mayer, B. Enzymatic function of nitric oxide synthases. Cardiovasc. Res., 1999, 43(3), 521-31.

[7] Shaul, P.W. Regulation of endothelial nitric oxide synthase: location, location, location. Annu. Rev. Physiol., 2002, 64, 749-74.

[8] Poulos, T.L.; Li, H. Structural basis for isoform-selective inhibition in nitric oxide synthase. Acc. Chem. Res., 2013, 46(2), 390-398.

[9] Zamora, R.; Vodovotz, Y.; Billiar, T.R. Inducible nitric oxide synthase and inflammatory diseases. Mol. Med., 2000, 6(5), 34773.

[10] Alderton, W.K.; Cooper, C.E.; Knowles, R.G. Nitric oxide synthases: structure, function and inhibition. Biochem. J., 2001, 357(3), 593-615.

[11] Sessa, W.C.; Forstermann, U. Nitric oxide synthases : regulation and function. Eur. Heart J., 2012, 33(7), 829-837.

[12] Hemmens, B.; Goessler, W.; Schmidt, K.; Mayer, B. Role of bound zinc in dimer stabilization but not enzyme activity of neuronal nitric-oxide synthase. J. Biol. Chem., 2000, 275(46), 35786-91.

[13] Li, H.; Raman, C.S.; Glaser, C.B.; Blasko, E.; Young, T. a.; Parkinson, J.F.; Whitlow, M.; Poulos, T.L. Crystal structures of zinc-free and bound heme domain of human inducible nitric-oxide synthase: Implications for dimer stability and comparison with endothelial nitric oxide synthase. J. Biol. Chem., 1999, 274(30), 21276-21284.

[14] Raman, C.S.; Li, H.; Martásek, P.; Král, V.; Masters, B.S.; Poulos, T.L. Crystal structure of constitutive endothelial nitric oxide synthase: a paradigm for pterin function involving a novel metal center. Cell, 1998, 95(7), 939-950.

[15] Abu-soud, H.M.; Yoho, L.; Stuehr, D.J. Calmodulin controls neuronal nitric-oxide synthase by a dual mechanism. J. Biol. Chem., 1994, 51(23), 8-11.

[16] Smith, B.C.; Underbakke, E.S.; Kulp, D.W.; Schief, W.R.; Marletta, M.A. Nitric oxide synthase domain interfaces regulate electron transfer and calmodulin activation. Proc. Natl. Acad. Sci. U. S. A., 2013, $110(38), 3577-3586$.

[17] Li, H.; Poulos, T.L. Structure-function studies on nitric oxide synthases. J. Inorg. Biochem., 2005, 99(1), 293-305.

[18] Giroud, C.; Moreau, M.; Mattioli, T. a; Balland, V.; Boucher, J.-L.; $\mathrm{Xu}-\mathrm{Li}$, Y.; Stuehr, D.J.; Santolini, J. Role of arginine guanidinium moiety in nitric-oxide synthase mechanism of oxygen activation. $J$. Biol. Chem., 2010, 285(10), 7233-7245.

[19] Gorren, A.C.F.; Mayer, B. Nitric-oxide synthase: a cytochrome P450 family foster child. Biochim. Biophys. Acta, 2007, 1770(3), 432-45.

[20] Förstermann, U.; Li, H. Therapeutic effect of enhancing endothelial nitric oxide synthase (eNOS) expression and preventing eNOS uncoupling. Br. J. Pharmacol., 2011, 164(2), 213-23.

[21] Roe, N.D.; Ren, J. Nitric oxide synthase uncoupling: a therapeutic target in cardiovascular diseases. Vascul. Pharmacol., 2012, 57(56), $168-72$

[22] Gorren, A.C.F.; Mayer, B. Tetrahydrobiopterin in nitric oxide synthesis: A novel biological role for pteridines. Curr. Drug Metab., 2002, 3(2), 133-157.

[23] Bian, K.; Murad, F. Nitric oxide (NO)--biogeneration, regulation, and relevance to human diseases. Font. Biosci., 2003, 1(8), 264278.

[24] Zhou, L.; Zhu, D. Nitric Oxide Neuronal nitric oxide synthase: Structure, subcellular localization, regulation, and clinical implications. Nitric Oxide, 2009, 20(4), 223-230.

[25] Zhang, Y.J.; Xu, Y.F.; Liu, Y.H.; Yin, J.; Wang, J.Z. Nitric oxide induces tau hyperphosphorylation via glycogen synthase kinase3beta activation. FEBS Lett., 2005, 579(27), 6230-6236.

[26] Gatto, E.M.; Riobó, N.A.; Carreras, M.C.; Cherñavsky, A.; Rubio, A.; Satz, M.L.; Poderoso, J.J. Overexpression of neutrophil neuronal nitric oxide synthase in Parkinson's disease. Nitric Oxide, 2000, 4(5), 534-9. 
[27] Thorns, V.; Hansen, L.; Masliah, E. nNOS expressing neurons in the entorhinal cortex and hippocampus are affected in patients with Alzheimer's disease. Exp. Neurol., 1998, 20(150), 14-20.

[28] Yao, J.K.; Leonard, S.; Reddy, R.D. Increased nitric oxide radicals in postmortem brain from patients with schizophrenia radical scavengers. Schizophr. Bull., 2004, 30(4), 923-934.

[29] Förstermann, U.; Sessa, W.C. Nitric oxide synthases: regulation and function. Eur. Heart J., 2012, 33(7), 829-837.

[30] Lounnas, V.; Ritschel, T.; Kelder, J.; Foloppe, N. Current progress in Structure-Based Rational Drug Design marks a new mindset in drug discovery. Comput. Struct. Biotechnol. J., 2013, 5(6), e201302011.

[31] Acharya, C.; Coop, A.; Polli, J.E.; MacKerell, A.D.J. Recent advances in ligand-based drug design: relevance and utility of the conformationally sampled pharmacophore approach. Curr Comput Aided Drug Des, 2011, 7(1), 10-22.

[32] Mukherjee, P.; Cinelli, M. a; Kang, S.; Silverman, R.B. Development of nitric oxide synthase inhibitors for neurodegeneration and neuropathic pain. Chem. Soc. Rev., 2014, 43(19), 6814-6838.

[33] Silverman, R.B. Design of selective neuronal nitric oxide synthase inhibitors for the prevention and treatment of neurodegenerative diseases. Acc. Chem. Res., 2009, 42(3), 439-51.

[34] Chreifi, G.; Li, H.; McInnes, C.R.; Gibson, C.L.; Suckling, C.J.; Poulos, T.L. Communication between the zinc and tetrahydrobiopterin binding sites in nitric oxide synthase. Biochemistry, 2014, 53(25), 4216-4223.

[35] Fröhlich, L.G.; Kotsonis, P.; Traub, H.; Taghavi-Moghadam, S.; Al-Masoudi, N.; Hofmann, H.; Strobel, H.; Matter, H.; Pfleiderer, W.; Schmidt, H.H. Inhibition of neuronal nitric oxide synthase by 4-amino pteridine derivatives: structure-activity relationship of antagonists of (6R)-5,6,7,8-tetrahydrobiopterin cofactor. J. Med. Chem., 1999, 42(20), 4108-4121.

[36] Matter, H.; Kotsonis, P.; Klingler, O.; Strobel, H.; Fröhlich, L.G.; Frey, A.; Pfleiderer, W.; Schmidt, H.H.H.W. Structural requirements for inhibition of the neuronal nitric oxide synthase (NOS-I): 3D-QSAR analysis of 4-oxo- and 4-amino-pteridinebased inhibitors. J. Med. Chem., 2002, 45(14), 2923-2941.

[37] Matter, H.; Kumar, H.S.A.; Fedorov, R.; Frey, A.; Kotsonis, P.; Hartmann, E.; Fröhlich, L.G.; Reif, A.; Pfleiderer, W.; Scheurer, P.; Ghosh, D.K.; Schlichting, I.; Schmidt, H.H.H.W. Structural analysis of isoform-specific inhibitors targeting the tetrahydrobiopterin binding site of human nitric oxide synthases. $J$. Med. Chem., 2005, 48(15), 4783-4792.

[38] Crane, B.R.; Arvai, A.S.; Ghosh, D.K.; Wu, C.; Getzoff, E.D.; Stuehr, D.J.; Tainer, J. a Structure of nitric oxide synthase oxygenase dimer with pterin and substrate. Science, 1998, 279(5359), 2121-2126.

[39] The PyMOL Molecular Graphics System, Version 1.5.0.4 Schrödinger, LLC.

[40] Ohashi, K.; Yamazaki, T.; Kitamura, S.; Ohta, S.; Izumi, S.; Kominami, S. Allosteric inhibition of rat neuronal nitric-oxide synthase caused by interference with the binding of calmodulin to the enzyme. Biochim. Biophys. Acta, 2007, 1770(2), 231-240.

[41] Li, W.; Fan, W.; Elmore, B.; Feng, C. Effect of solution viscosity on intraprotein electron transfer between the FMN and heme domains in inducible nitric oxide synthase. FEBS Lett., 2011, 585(16), 2622-2626

[42] Iyanagi, T.; Xia, C.; Kim, J.-J.P. NADPH-cytochrome P450 oxidoreductase: prototypic member of the diflavin reductase family. Arch. Biochem. Biophys., 2012, 528(1), 72-89.

[43] Ikura, M.; Barbato, G.; Klee, C.B.; Bax, A. Solution structure of calmodulin and its complex with a myosin light chain kinase fragment. Cell Calcium, 1992, 13(6), 391-400.

[44] Chattopadhyaya, R.; Meador, W.E.; Means, A.R.; Quiocho, F.A. Calmodulin structure refined at 1.7 A resolution. J. Mol. Biol., 1992, 228(4), 1177-1192.

[45] Aoyagi, M.; Arvai, A.S.; Tainer, J.A.; Getzoff, E.D. Structural basis for endothelial nitric oxide synthase binding to calmodulin. EMBO J., 2003, 22(4), 766-775.

[46] Renodon, A.; Boucher, J.L.; Sari, M.A.; Delaforge, M.; Ouazzani, J.; Mansuy, D. Strong inhibition of neuronal nitric oxide synthase by the calmodulin antagonist and anti-estrogen drug tamoxifen. Biochem. Pharmacol., 1997, 54(10), 1109-1114.

[47] Fukunaga, K.; Ohmitsu, M.; Miyamoto, E.; Sato, T. Inhibition of neuronal nitric oxide synthase by 3-[2-[4-(3-Chloro-2- methylphenyl)-1-piperazinyl]ethyl]-5,6-dimethoxy-1-(4-imida-zolylmethyl)-1H-indazole dihydrochloride 3.5 hydrate ( DY-9760e), a novel neuroprotective agent, In vitro and in cultured ne. Biochem. Pharmacol., 2000, 60(5), 693-699.

[48] Spratt, D.E.; Israel, O.K.; Taiakina, V.; Guillemette, J.G. Regulation of mammalian nitric oxide synthases by electrostatic interactions in the linker region of calmodulin. Biochim. Biophys. Acta, 2008, 1784(12), 2065-2070.

[49] Chen, P.F.; Wu, K.K. Two synthetic peptides corresponding to the proximal heme-binding domain and CD1 domain of human endothelial nitric-oxide synthase inhibit the oxygenase activity by interacting with CaM. Arch. Biochem. Biophys., 2009, 486(2), 132 140 .

[50] Win, N.H.H.; Ishikawa, T.; Saito, N.; Kato, M.; Yokokura, H.; Watanabe, Y.; Iida, Y.; Hidaka, H. A new and potent calmodulin antagonist, HF-2035, which inhibits vascular relaxation induced by nitric oxide synthase. Eur. J. Pharmacol., 1996, 299, 119-126.

[51] Zinzalla, G.; Thurston, D.E. Targeting protein-protein interactions for therapeutic intervention: a challenge for the future. Future Med. Chem., 2009, 1(1), 65-93.

[52] Beaumont, E.; Lambry, J.C.; Gautier, C.; Robin, A.C.; Gmouh, S.; Berka, V.; Tsai, A.L.; Blanchard-Desce, M.; Slama-Schwok, A. Synchronous photoinitiation of endothelial NO synthase activity by a nanotrigger targeted at its NADPH site. J. Am. Chem. Soc., 2007, 129(7), 2178-2186.

[53] Beaumont, E.; Lambry, J.C.; Robin, A.C.; Martasek, P.; BlanchardDesce, M.; Slama-Schwok, A. Two photon-induced electron injection from a nanotrigger in native endothelial NO-synthase. ChemPhysChem, 2008, 9(16), 2325-2331.

[54] Beaumont, E.; Lambry, J.C.; Blanchard-Desce, M.; Martasek, P.; Panda, S.P.; van Faassen, E.E.H.; Brochon, J.C.; Deprez, E.; Slama-Schwok, A. NO formation by neuronal NO-synthase can be controlled by ultrafast electron injection from a nanotrigger. ChemBioChem, 2009, 10(4), 690-701.

[55] Li, Y.; Wang, H.; Tarus, B.; Perez, M.R.; Morellato, L.; Henry, E.; Berka, V.; Tsai, A.-L.; Ramassamy, B.; Dhimane, H.; Dessy, C.; Tauc, P.; Boucher, J.-L.; Deprez, E.; Slama-Schwok, A. Rational design of a fluorescent NADPH derivative imaging constitutive nitric-oxide synthases upon two-photon excitation. Proc. Natl. Acad. Sci. USA, 2012, 109(31), 12526-12531.

[56] Víteček, J.; Lojek, A.; Valacchi, G.; Kubala, L. Arginine-based inhibitors of nitric oxide synthase: therapeutic potential and challenges. Mediators Inflamm., 2012, 2012, 1-22.

[57] Tafi, A.; Angeli, L.; Venturini, G.; Travagli, M.; Corelli, F.; Botta, M. Computational studies of competitive inhibitors of nitric oxide synthase (NOS) enzymes: Towards the development of powerful and isoform-selective inhibitors. Curr. Med. Chem., 2006, 13(16), 1929-1946.

[58] Moore, W.; Webber, R.K.; Fok, K. Inhibitors of human nitric oxide synthase isoforms with the carbamidine moiety as a common structural element. Bioorg. Med. Chem., 1996, 4(9), 1559-1564.

[59] Yuta, K.; Katsumi, I.; Kazumasa, S.; Yasuo, N.; Yukio, Y.; Keisuke, H. L-Nitroarginine increases blood presure in the rat. Clin. Exp. Pharmacol. Physiol., 1991, 18(6), 397-399.

[60] Hu, L.; Manning, R.D.; Brands, M.W. Long-term cardiovascular role of nitric oxide in conscious rats. Hypertension, 1994, 23(2), 185-194.

[61] Raman, C.S.; Li, H.; Martásek, P.; Southan, G.; Masters, B.S.S.; Poulos, T.L. Crystal structure of nitric oxide synthase bound to nitro indazole reveals a novel inactivation mechanism. Biochemistry, 2001, 40, 13448-13455.

[62] Hillier, B.J. Unexpected modes of PDZ domain scaffolding revealed by structure of nnos-syntrophin complex. Science (80-. )., 1999, 284(5415), 812-815.

[63] Tochio, H.; Zhang, Q.; Mandal, P. Solution structure of the extended neuronal nitric oxide synthase PDZ domain complexed with an associated peptide. Nat. Struct. Biol., 1999, 6(5), 417-421.

[64] Fedorov, R.; Vasan, R.; Ghosh, D.K.; Schlichting, I. Structures of nitric oxide synthase isoforms complexed with the inhibitor ARR17477 suggest a rational basis for specificity and inhibitor design. Proc. Natl. Acad. Sci. USA, 2004, 101(16), 5892-5897.

[65] Flinspach, M.L.; Li, H.; Jamal, J.; Yang, W.; Huang, H.; Hah, J.M.; Gómez-Vidal, J.A.; Litzinger, E. a; Silverman, R.B.; Poulos, T.L. Structural basis for dipeptide amide isoform-selective inhibition of neuronal nitric oxide synthase. Nat. Struct. Mol. Biol., 2004, 11(1), 54-59. 
[66] Ji, H.; Li, H.; Flinspach, M.; Poulos, T.L.; Silverman, R.B. Computer modeling of selective regions in the active site of nitric oxide synthases: implication for the design of isoform-selective inhibitors. J. Med. Chem., 2003, 46(26), 5700-5711.

[67] Morris, G.M.; Goodsell, D.S.; Halliday, R.S.; Huey, R.; Hart, W.E.; Belew, R.K.; Olson, A.J.; Al, M.E.T. Automated docking using a Lamarckian genetic algorithm and an empirical binding free energy function. J. Comput. Chem., 1998, 19(14), 1639-1662.

[68] Goodford, P.J. A computational procedure for determining energetically favorable binding sites on biologically important macromolecules. J. Med. Chem., 1985, 28(1), 849-857.

[69] Hagmann, W.K.; Caldwell, C.G.; Chen, P.; Durette, P.L.; Esser, C.K.; Lanza, T.J.; Kopka, I.E.; Guthikonda, R.; Shah, S.K.; MacCoss, M.; Chabin, R.M.; Fletcher, D.; Grant, S.K.; Green, B.G.; Humes, J.L.; Kelly, T.M.; Luell, S.; Meurer, R.; Moore, V.; Pacholok, S.G.; Pavia, T.; Williams, H.R.; Wong, K.K. Substituted 2-aminopyridines as inhibitors of nitric oxide synthases. Bioorg. Med. Chem. Lett., 2000, 10(17), 1975-1978.

[70] Tinker, A.; Beaton, H. 1, 2-Dihydro-4-quinazolinamines: potent, highly selective inhibitors of inducible nitric oxide synthase which show antiinflammatory activity in vivo. J. Med. Chem., 2003, 46(6), 913-916.

[71] Garcin, E.D.; Arvai, A.S.; Rosenfeld, R.J.; Kroeger, M.D.; Crane, B.R.; Andersson, G.; Andrews, G.; Hamley, P.J.; Mallinder, P.R.; Nicholls, D.J.; St-Gallay, S. a; Tinker, A.C.; Gensmantel, N.P.; Mete, A.; Cheshire, D.R.; Connolly, S.; Stuehr, D.J.; Aberg, A.; Wallace, A. V; Tainer, J. a; Getzoff, E.D. Anchored plasticity opens doors for selective inhibitor design in nitric oxide synthase. Nat. Chem. Biol., 2008, 4(11), 700-707.

[72] Ji, H.; Stanton, B.Z.; Igarashi, J.; Li, H.; Martásek, P.; Roman, L.J.; Poulos, T.L.; Silverman, R.B. Minimal pharmacophoric elements and fragment hopping, an approach directed at molecular diversity and isozyme selectivity. Design of selective neuronal nitric oxide synthase inhibitors. J. Am. Chem. Soc., 2008, 130(12), 3900-3914.

[73] Ji, H.; Li, H.; Martásek, P.; Roman, L.J.; Poulos, T.L.; Silverman, R.B. Discovery of highly potent and selective inhibitors of neuronal nitric oxide synthase by fragment hopping. J. Med. Chem., 2009, 52(3), 779-797.

[74] Bohm, H. The computer program LUDI: a new method for the de novo design of enzyme inhibitors. J. Comput. Aided Mol. Des., 1992, 6(1), 61-78.

[75] Ji, H.; Delker, S.L.; Li, H.; Martásek, P.; Roman, L.J.; Poulos, T.L.; Silverman, R.B. Exploration of the active site of neuronal nitric oxide synthase by the design and synthesis of pyrrolidinomethyl 2aminopyridine derivatives. J. Med. Chem., 2010, 53(21), 78047824.

[76] Huang, H.; Ji, H.; Li, H.; Jing, Q.; Labby, K.J.; Martásek, P.; Roman, L.J.; Poulos, T.L.; Silverman, R.B. Selective monocationic inhibitors of neuronal nitric oxide synthase. Binding mode insights from molecular dynamics simulations. J. Am. Chem. Soc., 2012, 134(28), 11559-11572.

[77] Xue, F.; Li, H.; Delker, S.L.; Fang, J.; Martásek, P.; Roman, L.J.; Poulos, T.L.; Silverman, R.B. Potent, highly selective, and orally bioavailable gem-difluorinated monocationic inhibitors of neuronal nitric oxide synthase. J. Am. Chem. Soc., 2010, 132(40), 1422914238

[78] Xue, F.; Li, H.; Fang, J.; Roman, L.J.; Martásek, P.; Poulos, T.L.; Silverman, R.B. Peripheral but crucial: a hydrophobic pocket (Tyr(706), Leu(337), and $\operatorname{Met}(336))$ for potent and selective inhibition of neuronal nitric oxide synthase. Bioorg. Med. Chem. Lett., 2010, 20(21), 6258-61.

[79] Li, H.; Xue, F.; Kraus, J.M.; Ji, H.; Labby, K.J.; Mataka, J.; Delker, S.L.; Martásek, P.; Roman, L.J.; Poulos, T.L.; Silverman, R.B. Cyclopropyl- and methyl-containing inhibitors of neuronal nitric oxide synthase. Bioorg. Med. Chem., 2013, 21(5), 1333-43.

[80] Xue, F.; Fang, J.; Delker, S.L.; Li, H.; Martásek, P.; Roman, L.J.; Poulos, T.L.; Silverman, R.B. Symmetric double-headed aminopyridines, a novel strategy for potent and membranepermeable inhibitors of neuronal nitric oxide synthase. J. Med. Chem., 2011, 54(7), 2039-2048.

[81] Delker, S.L.; Xue, F.; Li, H.; Jamal, J.; Silverman, R.B.; Poulos, T.L. Role of zinc in isoform-selective inhibitor binding to neuronal nitric oxide synthase . Biochemistry, 2010, 49(51), 10803-10.

[82] Nason, D.M.; Heck, S.D.; Bodenstein, M.S.; Lowe, J. a; Nelson, R.B.; Liston, D.R.; Nolan, C.E.; Lanyon, L.F.; Ward, K.M.; Volkmann, R. A substituted 6-phenyl-pyridin-2-ylamines: selective and potent inhibitors of neuronal nitric oxide synthase. Bioorg. Med. Chem. Lett., 2004, 14(17), 4511-4514.

[83] Oliveira, B.L.; Moreira, I.S.; Fernandes, P.A.; Ramos, M.J.; Santos, I.; Correia, J.D.G. Insights into the structural determinants for selective inhibition of nitric oxide synthase isoforms. J. Mol. Model., 2013, 19(4), 1537-1551.

[84] Delker, S.L.; Ji, H.; Li, H.; Jamal, J.; Fang, J.; Xue, F.; Silverman, R.B.; Poulos, T.L. Unexpected binding modes of nitric oxide synthase inhibitors effective in the prevention of a cerebral palsy phenotype in an animal model. J. Am. Chem. Soc., 2010, 132(15), 5437-5442.

[85] Xue, F.; Fang, J.; Lewis, W.W.; Martásek, P.; Roman, L.J.; Silverman, R.B. Potent and selective neuronal nitric oxide synthase inhibitors with improved cellular permeability. Bioorg. Med. Chem. Lett., 2010, 20(2), 554-557.

[86] Reif, W.D.; McCarthy, D.J.; Cregan, E.; Macdonald, E.J. Discovery and development of neuronal nitric oxide synthase inhibitors. Free Radic. Biol. Med., 2000, 28(10), 1470-1477.

[87] Liang, G.; Neuenschwander, K.; Chen, X.; Wei, L.; Munson, R.; Francisco, G.; Scotese, A.; Shutske, G.; Black, M.; Sarhan, S. Jiang, J.; Morize, I.; Vaz, R.J. Structure-based design, synthesis, and profiling of potent and selective neuronal nitric oxide synthase (nNOS) inhibitors with an amidinothiophene hydroxypiperidine scaffold. MedChem Comm, 2011, 2(3), 201.

[88] Ramnauth, J.; Renton, P. 1, 2, 3, 4-Tetrahydroquinoline-Based Selective Human Neuronal Nitric Oxide Synthase (nNOS) Inhibitors: Lead Optimization Studies Resulting in the Identification of N-(1-(2-(Methylamino)ethyl)-1,2,3,4tetrahydroquinolin-6-yl)thiophene-2-carboximidamide as. J. Med. Chem., 2012, 55(6), 2882-2893.

[89] Kim, S.H.; Chung, J.M. An experimental model for peripheral neuropathy produced by segmental spinal nerve ligation in the rat. Pain, 1992, 50(3), 355-363.

[90] Handy, R.L.; Harb, H.L.; Wallace, P.; Gaffen, Z.; Whitehead, K.J.; Moore, P.K. Inhibition of nitric oxide synthase by 1-(2trifluoromethylphenyl) imidazole (TRIM) in vitro: antinociceptive and cardiovascular effects. Br. J. Pharmacol., 1996, 119(2), 423431.

[91] Rogerson, T.; Wilkinson, C.; Hetarski, K. Steric factors in the inhibitory interaction of imidazoles with microsomal enzymes. Biochem. Pharmacol., 1977, 26(11), 1039-1042.

[92] Lee, Y.; Martasek, P.; Roman, L.J.; Masters, B.S.; Silverman, R.B. Imidazole-containing amino acids as selective inhibitors of nitric oxide synthases. Bioorg. Med. Chem., 1999, 7(9), 1941-1951.

[93] Ulhaq, S.; Chinje, E.C.; Naylor, M. a; Jaffar, M.; Stratford, I.J.; Threadgill, M.D. S-2-amino-5-azolylpentanoic acids related to Lornithine as inhibitors of the isoforms of nitric oxide synthase (NOS). Bioorg. Med. Chem., 1998, 6(11), 2139-2149.

[94] Freys, C.; Narayanans, K.; Mcmillano, K.; Grossll, S.S.; Masters, B.S. L-thiocitrulline: A stereospecific, heme-binding inhibitor of nitric oxide synthases. J. Biol. Chem., 1994, 269(42), 26083-26091.

[95] Litzinger, E.A.; Martásek, P.; Roman, L.J.; Silverman, R.B. Design, synthesis, and biological testing of potential hemecoordinating nitric oxide synthase inhibitors. Bioorg. Med. Chem., 2006, 14(9), 3185-3198.

[96] Rarey, M.; Wefing, S.; Lengauer, T. Placement of medium-sized molecular fragments into active sites of proteins. J. Comput. Aided. Mol. Des., 1996, 10(1), 41-54.

[97] Martell, J.D.; Li, H.; Doukov, T.; Martásek, P.; Roman, L.J.; Soltis, M.; Poulos, T.L.; Silverman, R.B. Heme-coordinating inhibitors of neuronal nitric oxide synthase. Iron-thioether coordination is stabilized by hydrophobic contacts without increased inhibitor potency. J. Am. Chem. Soc., 2010, 132(2), 798-806.

[98] Jenkins, J.; Kao, R.; Shapiro, R. Virtual screening to enrich hit lists from high-throughput screening: A case study on small-molecule inhibitors of angiogenin. Proteins Struct. Funct., 2003, 50(1), 8193.

[99] Xu, G.; Chen, Y.; Shen, K.; Wang, X.; Li, F.; He, Y. The discovery of potentially selective human neuronal nitric oxide synthase (nNOS) Inhibitors: a combination of pharmacophore modelling, CoMFA, virtual screening and molecular docking studies. Int. J. Mol. Sci., 2014, 15(5), 8553-8569.

[100] Jackson, R. Q-fit: a probabilistic method for docking molecular fragments by sampling low energy conformational space. $J$. Comput. Aided Mol. Des., 2002, 16(1), 43-57. 
[101] Kumar, V.; Gupta, S. A QSAR and molecular modeling study on a series of 3,4-dihydro-1-isoquinolinamines and thienopyridines acting as nitric oxide synthase inhibitors. Indian J. Biochem. Biophys., 2013, 50(1), 72-79.

[102] Pajouhesh, H.; Lenz, G. Medicinal chemical properties of successful central nervous system drugs. J. Am. Soc. Exp. Neurother., 2005, 2(4), 541-553.

[103] Huang, H.; Silverman, R. Recent advances toward improving the bioavailability of neuronal nitric oxide synthase inhibitors. Curr. Top. Med. Chem., 2013, 13(7), 803-812.

[104] Li, H.; Xue, F.; Kraus, J.M.; Ji, H.; Labby, K.J.; Mataka, J.; Delker, S.L.; Martásek, P.; Roman, L.J.; Poulos, T.L.; Silverman, R.B. Cyclopropyl- and methyl-containing inhibitors of neuronal nitric oxide synthase. Bioorg. Med. Chem., 2013, 21(5), 1333-1343.

[105] Lawton, G.R.; Ralay Ranaivo, H.; Chico, L.K.; Ji, H.; Xue, F.; Martásek, P.; Roman, L.J.; Watterson, D.M.; Silverman, R.B. Analogues of 2-aminopyridine-based selective inhibitors of neuronal nitric oxide synthase with increased bioavailability. Bioorg. Med. Chem., 2009, 17(6), 2371-2380.

[106] Silverman, R.B.; Lawton, G.R.; Ralay Ranaivo, H.; Chico, L.K.; Seo, J.; Watterson, D.M. Effect of potential amine prodrugs of selective neuronal nitric oxide synthase inhibitors on blood-brain barrier penetration. Bioorg. Med. Chem., 2009, 17(21), 7593-7605.

[107] Kuhn, B.; Mohr, P.; Stahl, M. Intramolecular hydrogen bonding in medicinal chemistry. J. Med. Chem., 2010, 53(6), 2601-2611.

[108] Jansma, A.; Zhang, Q.; Li, B.; Ding, Q.; Uno, T.; Bursulaya, B.; Liu, Y.; Furet, P.; Gray, N.S.; Geierstanger, B.H. Verification of a designed intramolecular hydrogen bond in a drug scaffold by nuclear magnetic resonance spectroscopy. J. Med. Chem., 2007, 50(24), 5875-5877.

[109] Laurence, C.; Brameld, K. a; Graton, J.; Le Questel, J.-Y.; Renault, E. The $\mathrm{pK}(\mathrm{BHX})$ database: toward a better understanding of hydrogen-bond basicity for medicinal chemists. J. Med. Chem., 2009, 52(14), 4073-4086.

[110] McDonagh, A.F.; Lightner, D.A. Influence of conformation and intramolecular hydrogen bonding on the acyl glucuronidation and biliary excretion of acetylenic bis-dipyrrinones related to bilirubin. J. Med. Chem., 2007, 50(3), 480-488.

[111] Sasaki, S.; Cho, N.; Nara, Y.; Harada, M.; Endo, S.; Suzuki, N. Furuya, S.; Fujino, M. Discovery of a thieno[2,3-d]pyrimidine-2,4dione bearing a p-methoxyureidophenyl moiety at the 6-position: a highly potent and orally bioavailable non-peptide antagonist for the human luteinizing hormone-releasing hormone receptor. J. Med. Chem., 2003, 46(1), 113-124.

[112] Labby, K.J.; Xue, F.; Kraus, J.M.; Ji, H.; Mataka, J.; Li, H.; Martásek, P.; Roman, L.J.; Poulos, T.L.; Silverman, R.B. Intramolecular hydrogen bonding: a potential strategy for more bioavailable inhibitors of neuronal nitric oxide synthase. Bioorg. Med. Chem., 2012, 20(7), 2435-2443.

[113] Kumar, R.; Sharma, A.; Tiwari, R.K. Can we predict blood brain barrier permeability of ligands using computational approaches? Interdiscip. Sci., 2013, 5(2), 95-101.

[114] Ji, H.; Tan, S.; Igarashi, J.; Li, H.; Derrick, M.; Martásek, P. Roman, L.J.; Vásquez-Vivar, J.; Poulos, T.L.; Silverman, R.B. Selective neuronal nitric oxide synthase inhibitors and the prevention of cerebral palsy. Ann. Neurol., 2009, 65(2), 209-217.

[115] Kartasasmitaa, R.; Musfiroha, I. Binding affinity of asiatic acid derivatives design against inducible nitric oxide synthase and ADMET prediction. J. Appl. Pharm. Sci., 2014, 4(02), 75-80.

[116] Li, H.; Jamal, J.; Plaza, C.; Pineda, S.H.; Chreifi, G.; Jing, Q.; Cinelli, M.A.; Silverman, R.B.; Poulos, T.L. Structures of human constitutive nitric oxide synthases. Acta Crystallogr. D. Biol. Crystallogr., 2014, 70(10), 2667-2674. 